\title{
How may tropical cyclones change in a warmer climate?
}

\author{
By LENNART BENGTSSON ${ }^{1,2}$, KEVIN I. HODGES ${ }^{1 *}$, MONIKA ESCH $^{2}$, \\ NOEL KEENLYSIDE ${ }^{3}$, LUIS KORNBLUEH ${ }^{2}$, JING-JIA LUO ${ }^{4}$ and TOSHIO YAMAGATA ${ }^{4}$, \\ ${ }^{1}$ Environmental Systems Science Centre, University of Reading, Whiteknights, PO Box 238, Reading, RG6 6AL, UK; \\ ${ }^{2}$ Max Planck Institute for Meteorology, Bundesstraße 53, 20146 Hamburg, Germany; ${ }^{3}$ Leibniz Institute of Marine \\ Sciences, IFM-GEOMAR, Düsternbrooker Weg 20, D-24105 Kiel, Germany; ${ }^{4}$ Climate Variations Research Program, \\ Frontier Research Center for Global Change (FRCGC), 3173-25 Showamachi, Kanazawa-ku, Yokohama City, \\ Kanagawa 236-0001, Japan
}

(Manuscript received 22 January 2007; in final form 13 April 2007)

\begin{abstract}
Tropical cyclones (TC) under different climate conditions in the Northern Hemisphere have been investigated with the Max Planck Institute (MPI) coupled (ECHAM5/MPI-OM) and atmosphere (ECHAM5) climate models. The intensity and size of the TC depend crucially on resolution with higher wind speed and smaller scales at the higher resolutions. The typical size of the TC is reduced by a factor of 2.3 from T63 to T319 using the distance of the maximum wind speed from the centre of the storm as a measure. The full three-dimensional structure of the storms becomes increasingly more realistic as the resolution is increased.

For the T63 resolution, three ensemble runs are explored for the period 1860 until 2100 using the IPCC SRES scenario A1B and evaluated for three $30 \mathrm{yr}$ periods at the end of the 19th, 20th and 21st century, respectively. While there is no significant change between the 19th and the 20th century, there is a considerable reduction in the number of the TC by some $20 \%$ in the 21 st century, but no change in the number of the more intense storms. Reduction in the number of storms occurs in all regions. A single additional experiment at T213 resolution was run for the two latter 30-yr periods. The T213 is an atmospheric only experiment using the transient sea surface temperatures (SST) of the T63 resolution experiment. Also in this case, there is a reduction by some $10 \%$ in the number of simulated TC in the 21 st century compared to the 20th century but a marked increase in the number of intense storms. The number of storms with maximum wind speeds greater than $50 \mathrm{~m} \mathrm{~s}^{-1}$ increases by a third. Most of the intensification takes place in the Eastern Pacific and in the Atlantic where also the number of storms more or less stays the same.

We identify two competing processes effecting TC in a warmer climate. First, the increase in the static stability and the reduced vertical circulation is suggested to contribute to the reduction in the number of storms. Second, the increase in temperature and water vapour provide more energy for the storms so that when favourable conditions occur, the higher SST and higher specific humidity will contribute to more intense storms. As the maximum intensity depends crucially on resolution, this will require higher resolution to have its full effect. The distribution of storms between different regions does not, at first approximation, depend on the temperature itself but on the distribution of the SST anomalies and their influence on the atmospheric circulation.

Two additional transient experiments at T319 resolution where run for $20 \mathrm{yr}$ at the end of the 20th and 21st century, respectively, using the same conditions as in the T213 experiments. The results are consistent with the T213 study. The total number of TC were similar to the T213 experiment but were generally more intense. The change from the 20th to the 21 st century was also similar with fewer TC in total but with more intense cyclones.
\end{abstract}

\footnotetext{
*Corresponding author.

e-mail: kih@mail.nerc-essc.ac.uk

DOI: $10.1111 / \mathrm{j} .1600-0870.2007 .00251 . \mathrm{x}$
} 


\section{Introduction}

The question of how tropical storms may change in a warmer climate has been discussed extensively. The importance of higher sea surface temperature (SST) is supported from theoretical studies (Emanuel, 1988; Holland, 1997) showing a direct relation between the maximum intensity of tropical storms and SST. This is further underpinned by several recent studies claiming an increase in the intensity of hurricanes in the last two decades (Webster et al., 2005; Sriver and Huber, 2006) with the general increase in tropical SST. Some studies have used the cube of the maximum wind speed, or the power dissipation index (PDI) (Emanuel, 1987), integrated over the lifetime of individual storms where the PDI is considered as a suitable measure of the destructive power of the storm (Bister and Emanuel, 1998). However, to reliably observe small changes in maximum wind speed and to determine robust trends over time when observing systems have undergone major changes has been seriously questioned (Chan, 2006; Klotzbach, 2006; Landsea et al., 2006). The large interannual variation in the numbers of tropical storms indicates that other factors such as variations in the atmospheric circulation are important. Thus the question as to what may happen to tropical storms in a warmer climate must consequently consider associated changes in the atmospheric general circulation.

Based on empirical evidence, Gray (1979) has suggested that tropical storms not only depend on the SST and the heat content in the upper ocean layer but also to a large degree on the atmospheric conditions. High static stability, low relative humidity and high vertical wind shear all have a significant negative impact on the development of tropical cyclones (TC). The reduced number of hurricanes in the Atlantic during El Niño, for example, is related to increased vertical wind shear and to a superimposed subsidence effect in the regions of the Atlantic where tropical storms normally develop (Wu and Lau, 1992). See also, Tang and Neelin (2004) who considered the role of lapse rate changes on hurricanes in the Atlantic associated with ENSO.

As numerical models improve they are gradually becoming more reliable in predicting tropical storms several days in advance. Large progress has taken place in predicting the movement of the storms whilst predicting the intensity and its variations still have considerable deficiencies (DeMaria et al., 2005). However, given sufficient resolution and suitable parametrization of relevant physical processes such as explicit treatment of penetrating moist convection, progress can be found in intensity prediction as well (Krishnamurti et al., 2005; Shen et al., 2006). These improvements and the ability to run climate models at higher resolution introduces the possibility for investigating the impact of climate change on more realistically simulated tropical storms.

There have been several model studies over the last decade that explore possible changes of tropical storms in a future climate. Three different approaches are followed. In one approach the predictors for the development of tropical storms, as identified by Gray (1979), have been used (Ryan et al., 1992; Watterson et al., 2005). Such assessments are attractive as they can be applied to model integrations at low resolutions. These studies generally overestimate the importance of SST, which has led to attempts to modify the thermal indices as suggested by Gray (1979). For example, Royer et al. (1998) replaced Gray's thermodynamic predictors with a single measure of moist static stability as calculated by the model. Chauvin et al. (2006) recently claimed some success with this approach.

In a second approach TC are identified per se in the model according to specific selection criteria such as a warm core and maximum wind speed in the lower troposphere and central surface pressure (Bengtsson et al., 1995). This is a direct approach but requires sufficient model resolution in order to simulate realistic vortices. Recent high-resolution studies include those of Sugi et al. (2002), Chauvin et al. (2006) and Oouchi et al. (2006).

Finally, in a third approach, limited area models at high resolution are used driven by the atmospheric boundary conditions of the large-scale model and the SST, (Knutson et al., 1998; Knutson and Tuleya, 2004). This is an efficient method as high resolution can be used with limited computer resources. However, the genesis of storms cannot normally be realistically simulated in these experiments and therefore the large-scale boundary conditions will have to be prescribed or provided by a global model. In some experiments an initial onset vortex has also been introduced into the model to create suitable initial conditions for a tropical cyclone to develop (Knutson and Tuleya, 1999).

The most straightforward approach is the second one, but studies so far have been hampered by difficulties in running global models at sufficient resolution to be able to resolve the more intense features of tropical storms. The large-scale model experiments have also given inconclusive results; some models show a marked sensitivity to the parametrizations such as for clouds (Broccoli and Manabe, 1990) whilst some models show an increase in the number of tropical storms and others a reduction. The most common result is a reduction in the number of TC in a warmer climate (Bengtsson et al., 1996; Sugi et al., 2002; Oouchi et al., 2006; Yoshimura et al., 2006), although this does not exclude the occurrence of more intense storms in the warmer climate (e.g. Oouchi et al., 2006).

In a recent study (Bengtsson et al., 2007) TC were explored using a T159 version of the ECHAM5 model with prescribed SST for the period 1978-1999 using the AMIP2 protocol (WGNE, 1996). The model-generated TC where compared both with TC identified in recent re-analysis data and with observed tropical storms from the Tropical Warning Centres (TWC). It was noted that the model agrees well with the recent ERA40 re-analysis, both with respect to number, distribution and interannual variability of storms. Compared to observed storms, the model, and to an even greater degree the re-analyses, underestimate the intensity of the storms. It was concluded that a major cause of this 
is insufficient resolution. This paper will consider resolution aspects and has the objective of exploring how TC may change in a warmer climate and how this change may depend on resolution. The main comparison will be between integrations of a coupled T63 version of the ECHAM5 model and a T213 resolution time-slice integration with some additional evaluation of a T319 resolution time-slice integration.

The following science objectives will be addressed.

1. How do TC respond to anthropogenic climate change and how does this depend on resolution?

2. What changes occur in intensity, lifetime and PDI?

3. What possible mechanisms control any changes in TC? What are the dominant factors?

The paper continues in Section 2 with a description of the experiments, Section 3 shows the structure and typical evolution of TC at different resolutions, Section 4 summarizes the results of the T63 experiments for the $30 \mathrm{yr}$ periods at the end of the 19th, 20 th and 21 st century, respectively. Section 5 extends this to the time-slice experiments at T213 resolution. In Section 6 we analyse the consequences of changes in the hydrological cycle and in Section 7 we discuss some additional time-slice experiments at $\mathrm{T} 319$ resolution.

\section{Experimental design and analysis methodology}

For this work, we have used recent climate change experiments with the Max Planck Institute for Meteorology (Jungclaus et al., 2006) ECHAM5/MPI-OM coupled model at several resolutions. This model does not employ any flux adjustment. The first set of experiments we have explored have been produced by the model at an atmospheric resolution represented by 63 spectral modes with triangular truncation and 31 levels in the vertical (T63L31, $192 \times 96$ grid). We have evaluated an ensemble of three climate change experiments made with this model based on the SRES A1B scenario (Nakicenovic et al., 2000). The ensemble members have been run with the same coupled model and under the same atmospheric forcing but starting from different ocean and atmospheric states obtained from a $500 \mathrm{yr}$ pre-industrial integration with the same model but with pre-industrial concentrations of carbon dioxide, methane and nitrous oxide. The climate change experiments are part of the IPCC 4th assessment (Roeckner et al., 2006). We have chosen three periods from the integrations that represent the end of the 19th century (1861-1890), the end of the 20th century (1961-1990) and the end of the 21st century (2071-2100). We will use the notation 19C, 20C and 21C, respectively, for these periods throughout the rest of the paper. For the first two periods both observed and reconstructed concentrations of greenhouse gases and sulphate aerosols are used. The well-mixed greenhouse gases $\left(\mathrm{CO}_{2}, \mathrm{CH}_{4}, \mathrm{~N}_{2} \mathrm{O}, \mathrm{F} 11, \mathrm{~F} 12\right.$ and minor halocarbons) were prescribed as annual global means according to observations (fit to ice core data and direct observations). Monthly data of stratospheric and tropospheric ozone concentrations were prescribed as two-dimensional (latitude and height) distributions. The space-time distribution of sulphate aerosols was prescribed using the data from an offline simulation (Pham et al., 2005). Both the direct and first indirect (cloud albedo) effect of sulphate aerosols were included. Analysis of the SST show there is only a minor increase between $19 \mathrm{C}$ and $20 \mathrm{C}$ (an average of $0.2 \mathrm{~K}$ in the tropics and subtropics) but a considerable increase between the $20 \mathrm{C}$ and $21 \mathrm{C}$. The observed changes for the earlier period are slightly larger, with a best estimate of $\sim 0.28 \mathrm{~K}$, as calculated from HadSST2 (Rayner et al., 2006). In the northern Hemisphere tropics and subtropics the SST warming in the latter period is generally above $2 \mathrm{~K}$ and in some areas around $3 \mathrm{~K}$ as shown in Fig. 1. Further analysis of these integrations has shown that they give a realistic description of the El Niño-Southern Oscillation (ENSO) (Oldenborgh et al., 2005) and storm tracks both in the extratropics and the tropics

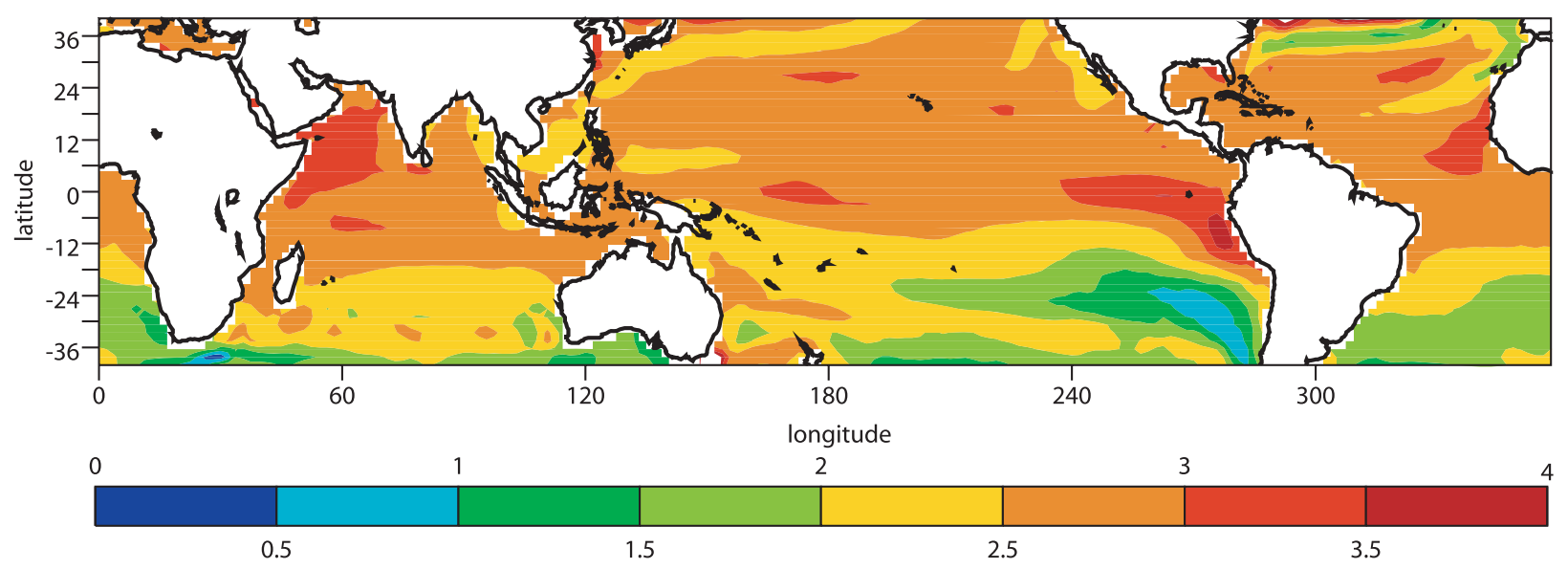

Fig. 1. Difference in averaged SST's between 1961-1990 and 2071-2100, averaged over the T63 three ensemble members for the NH tropics and subtropics. 
(Bengtsson et al., 2006). The model also gives a good description of tropical intraseasonal variability (Lin et al., 2006).

For the same two latter periods of $20 \mathrm{C}$ and $21 \mathrm{C}$ we also explore integrations at T213 resolution $(640 \times 320$ grid $)$, using the atmosphere only component of the model and the so-called 'time-slice' method (Bengtsson et al., 1996; IPCC 2001). The T213 integration used the same atmospheric composition as the T63 run. For the boundary conditions the time varying SST fields from one of the T63 coupled model runs where used. Unfortunately, it has since been discovered that there was a problem with the specification of sea ice in the T213 integration. However, by inspecting several fields the impact of this error was found to be confined to the high latitudes and hence we believe this error will have no impact on the TC studied here. We also explore a further two time-slice integrations for the periods 1980-2000 and 20802100 , respectively, made with the same model but at resolution T319 $(960 \times 480$ grid). However, the main comparison will be made between the T63 and T213 experiments since these are the most consistent in terms of time periods and available fields (only a limited number of fields and levels where archived for T319 due to storage limitations).

In order to keep the discussion to a manageable size we here restrict the study of the TC to the Northern Hemisphere, the Southern Hemisphere will be considered in a future study. In order to identify TC we employ a new search method making use of the full three-dimensional (3-D) structure of the vortices. Initially all vortices are identified and tracked during their full life cycle, from their generation as weak initial vortices to their decay possibly at high latitudes. This uses the same approach as in Thorncroft and Hodges (2001) for the tracking but extended to higher latitudes and as used in Bengtsson et al. (2007). In fact, the region considered is $(0,60) \mathrm{N}$. For the initial identification and tracking six hourly, $850 \mathrm{hPa}$ relative vorticity is used. The TC are identified from amongst all the candidate tracks by requiring them to have a coherent vertical structure and warm core, which means that the relative vorticity decreases with height. A minimum reduction of vorticity of $6 \times 10^{-5} \mathrm{~s}^{-1}$ ( $\xi_{\text {diff }}$ ) between 850 and $250 \mathrm{hPa}$ is used to identify the warm core eddies at a T63 resolution as well as an intensity threshold $\left(\xi_{\text {int }}\right)$ at $850 \mathrm{hPa}$ of $6 \times 10^{-5} \mathrm{~s}^{-1}$. The coherent vertical structure is determined by requiring that a positive vorticity centre exists at all available levels between 850 and $250 \mathrm{hPa}$. These three criteria are then required to be attained for a minimum number of consecutive time steps $(n)$, which we here take to be $4(1 \mathrm{~d})$ for a storm to be considered a TC. The criteria are specified throughout the paper as the triplet $\left(\xi_{\text {int }}, \xi_{\text {diff }}, n\right)$ with the vorticity scaled by $10^{-5}$. Full details of the TC identification and calibration can be found in Bengtsson et al. (2007). Note, using this approach we obtain the full life cycle of vortices that are defined as TC for only part of their lifecycle.

As has been discussed by Walsh et al. (2007), the number of TC at a given intensity either in vorticity or in wind speed depends on resolution. This can be seen from Table 1 which
Table 1. Number of TC per year for different values of ( $\left.\xi_{\text {int }}, \xi_{\text {diff }}, n\right)$ for the period 1961-1990. T63 averaged over the three ensemble members. For $(6,0,4)$ the vertical consistency check is switched off. See text for further information

\begin{tabular}{lccccc}
\hline & $(6,0,4)$ & $(6,3,4)$ & $(6,6,4)$ & $(6,12,4)$ & $(12,6,4)$ \\
\hline T63 & 187 & 71 & 33 & 3 & 18 \\
T213 & 306 & 172 & 105 & 28 & 62 \\
\hline
\end{tabular}

summarizes the number of vortices per year for different choices of identification criteria $\left(\xi_{\text {int }}, \xi_{\text {diff }}, n\right)$ for both the T63 and T213 experiments. As will be shown below this is also the case for the vertical structure and the warm core, which is less pronounced at the lower T63 resolution. However, in this study where the main emphasis is to compare the change of TC in a warmer climate and its dependence on resolution we maintain for the sake of clarity and consistency the same definition of a TC as in our previous study (Bengtsson et al., 2007), namely ( $\left.\xi_{\text {int }}, \xi_{\text {diff }}, n\right) \equiv$ $(6,6,4)$.

\section{The structure of TC at different horizontal resolutions}

To determine how realistic the TC are in terms of their full 3-D structure we have explored 3-D composites of the TC for the 100 most intense storms (in terms of the vorticity) for vorticity, winds and temperature anomaly, for each of the resolutions (T63, T213 and T319). To determine the composites we introduce a new approach which determines the composites directly on the sphere, in a radial coordinate, system centred on the storms, so negating any bias that can be introduced when producing composites of storms from different latitudes on a latitude-longitude grid (cylindrical projection). The approach is described in the appendix. Note, that in this presentation no attempt has been made to orientate the grid with the propagation direction (see Appendix). Frank (1977) suggests that ignoring the direction of propagation is the preferred method of producing composites but this will be explored further in the future. Whilst this unbiased approach to computing the composites is perhaps not critical for TC, which mostly occur at tropical latitudes, or where a single storm is considered, some storms do indeed exist as TC going into the mid-latitudes and hence we believe this approach is valid. In addition, in future work we want to explore the extratropical transition where this could be more critical.

Since the main aim of this paper is the influence of climate change on TC, only a limited number of the possible structure diagnostics are presented and a more detailed view of the structure of TC, including the influence of storm propagation on asymmetries in such variables as the wind field will be left to a future publication. The composites have been produced from the time points where each storm attains its maximum intensity on levels from 925 to $50 \mathrm{hPa}$ for $\mathrm{T} 63$ and $\mathrm{T} 213$, for T319 due to the more 


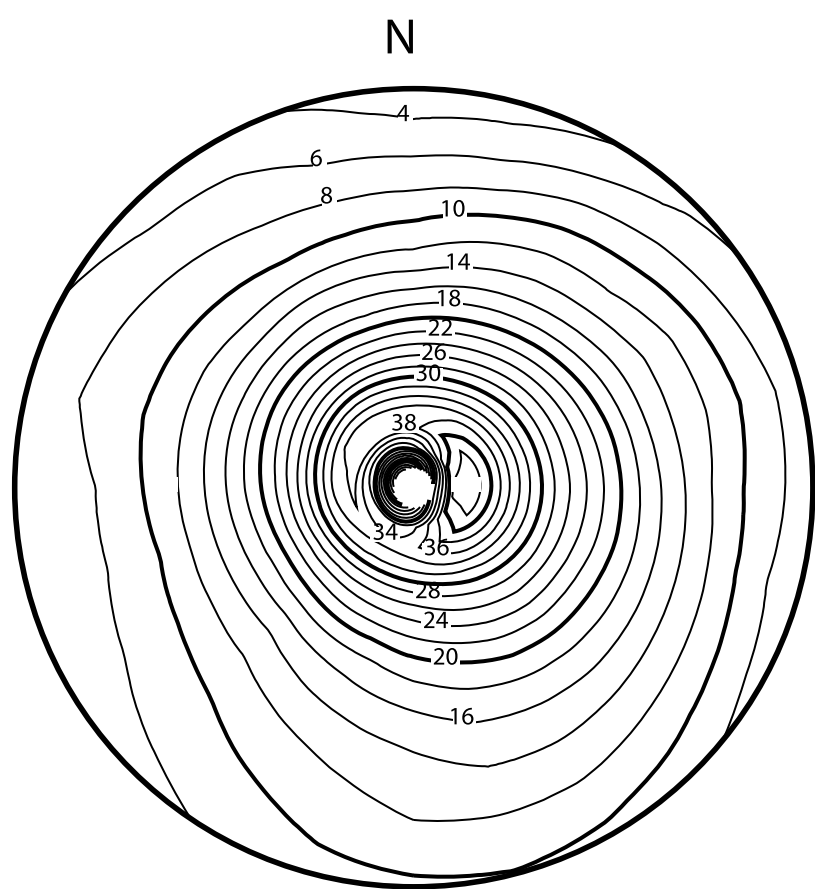

(a) Tangential

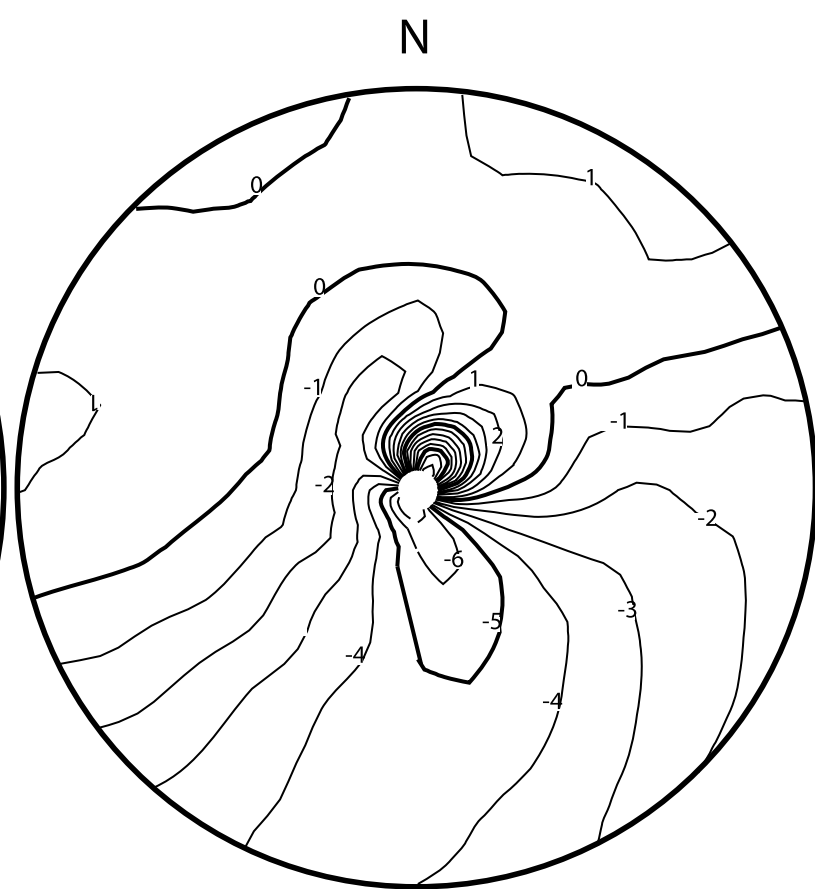

(b) Radial

Fig. 2. Two-dimensional composites on a $10^{\circ}$ radius, storm centred region, of (a) tangential and (b) radial winds at $850 \mathrm{hPa}$ of the $100 \mathrm{most}$ intense storms from the $\mathrm{T} 213$ experiment in units of $\mathrm{m} \mathrm{s}^{-1}$. Bold contours are every 10 and $5 \mathrm{~m} \mathrm{~s}^{-1}$ for tangential and radial winds, respectively. Cyclonic flow is positive for tangential winds and inflow is denoted by negative values and outflow by positive values for the radial wind.

limited availability of levels, levels between 850 and $300 \mathrm{hPa}$ have been used. The maximum intensity is most likely to occur for storms as they recurve and hence are moving polewards. This therefore represents a particular stage of storm development whereas previous attempts at producing composites have averaged storms for all time points where the storm is defined as a TC and so mixing different stages of storm development. The radial grid is defined on a spherical cap with radius of $10^{\circ}$ with 20 subdivisions $\left(0.5^{\circ}\right)$ in the radial direction and $24\left(15^{\circ}\right)$ in the azimuthal direction.

The wind field is generally the most asymmetric of the fields usually considered when discussing TC, as shown in several observational studies, for example, Frank (1977) and Kepert (2006a,b), with the asymmetry dependent on the propagation direction of the storm. Here the direction of the storm is more or less factored out by choosing the single time point of the maximum intensity of each storm for the composites. These studies have shown that there are strong asymmetries in the west-east direction for the tangential wind and south-north for the radial wind. In Fig. 2 we show the 2-D horizontal composite of the tangential and radial winds at $850 \mathrm{hPa}$ for the T213 experiment. These are in broad agreement with the observational studies (Frank, 1977; Kepert, 2006a,b) with stronger tangential winds to the east (Fig. 2a) of the storm centre and a marked asymmetry in the radial winds (Fig. 2b) with the inflow region being to the south of the composite storm centre and weaker outflow to the north though with stronger outflow close to the storm centre to the northeast. This pattern persists with height with the tangential winds weakening and the radial wind pattern becoming stronger with much stronger outflow aloft. This asymmetry is taken into account when we consider the impact of the horizontal resolution on the vertical structure of the wind field, by producing cross-sections rather than azimuthal averages. This is shown in Fig. 3 for each resolution for west-east cross sections with height of the tangential wind and south-north of the radial wind. For the tangential wind it is apparent that the west-east asymmetry exists through the depth of the storm with the highest winds to the east. These occur at a radial distance of $3.5^{\circ}$ for the T63 resolution, $1.5^{\circ}$ for $\mathrm{T} 213$ and a little less than this for T319. It is also apparent that the maximum wind speed, at $850 \mathrm{hPa}$, increases with resolution from $\sim 24 \mathrm{~m} \mathrm{~s}^{-1}$ for T63 to $\sim 50 \mathrm{~m} \mathrm{~s}^{-1}$ for T319. The radial winds (Fig. 3) clearly show the south-north asymmetry with inflow to the south and outflow to the north, this pattern persisting throughout the depth of the composite storm. At the lowest level of $925 \mathrm{hPa}$ there is inflow both to the south and north with the strongest inflow occurring to the south. The outflow in the uppermost levels occurs both to the north and south with the strongest outflow occurring to the north at $200 \mathrm{hPa}$ and weaker outflow to the south at $100 \mathrm{hPa}$. If we azimuthally average the radial wind (not shown) this highlights the dominance of inflow 


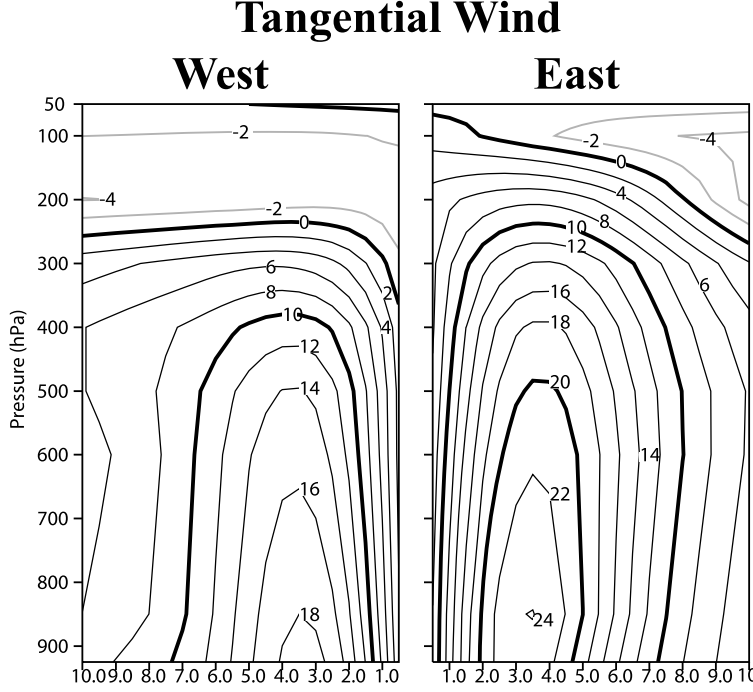

(a)

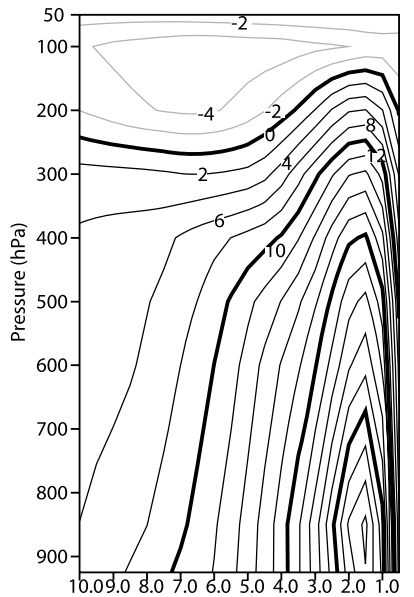

(c)

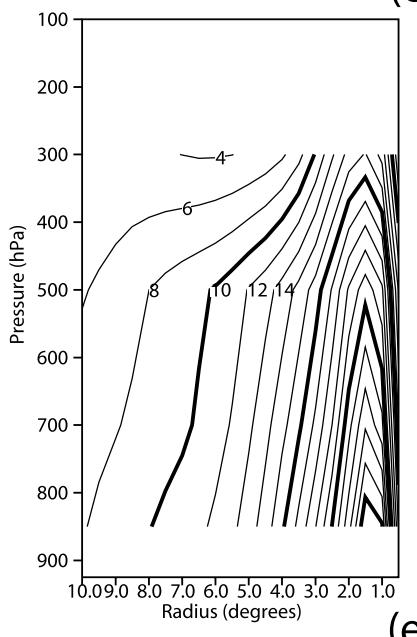

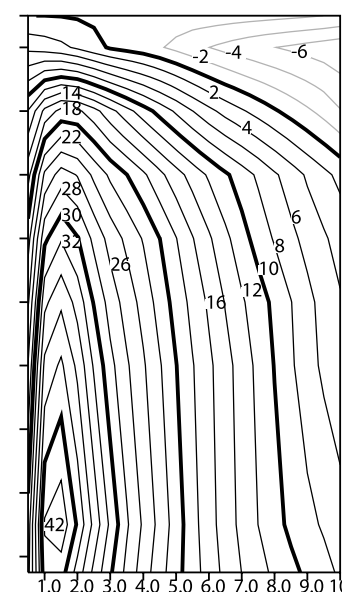

(c)

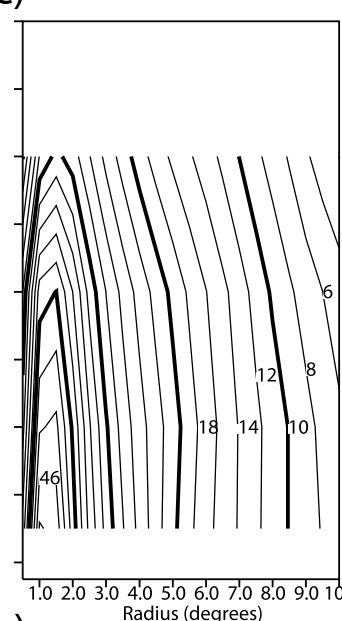

(e)

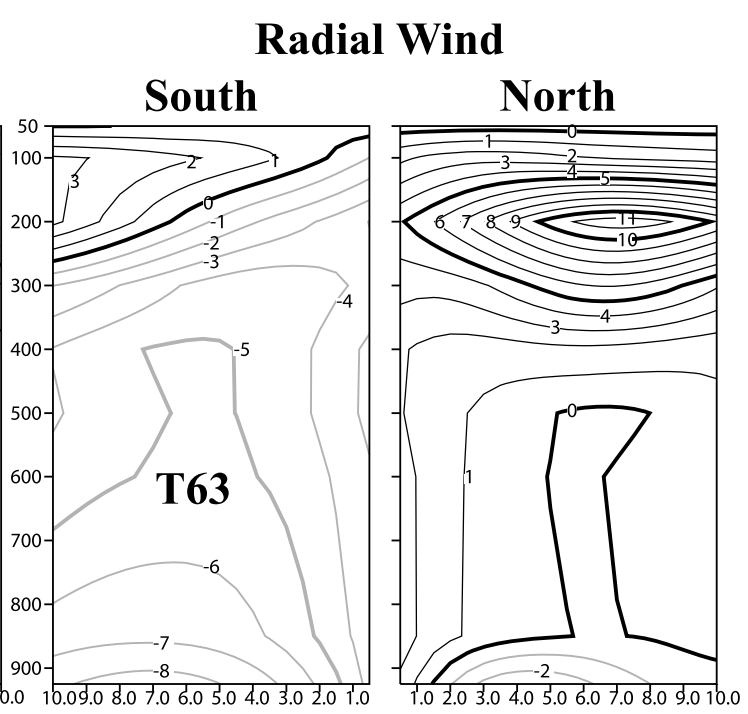

(b)

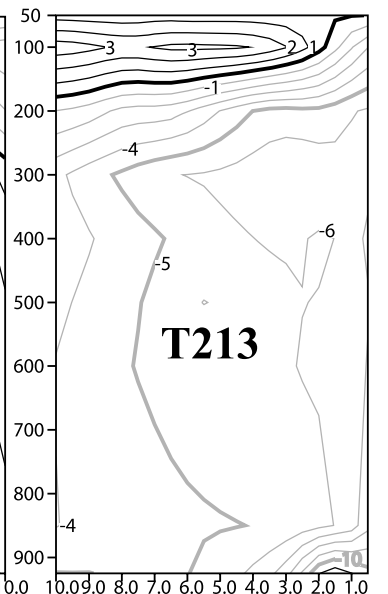

(d)

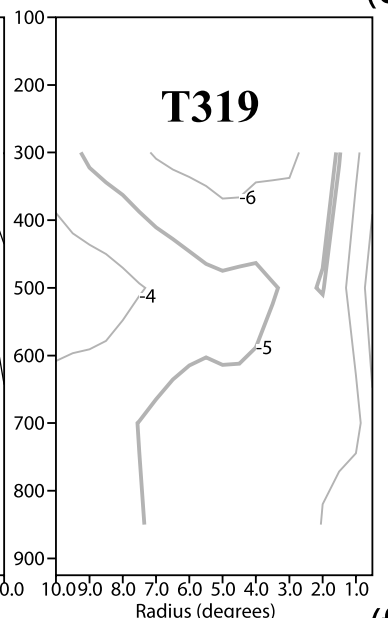

(f)
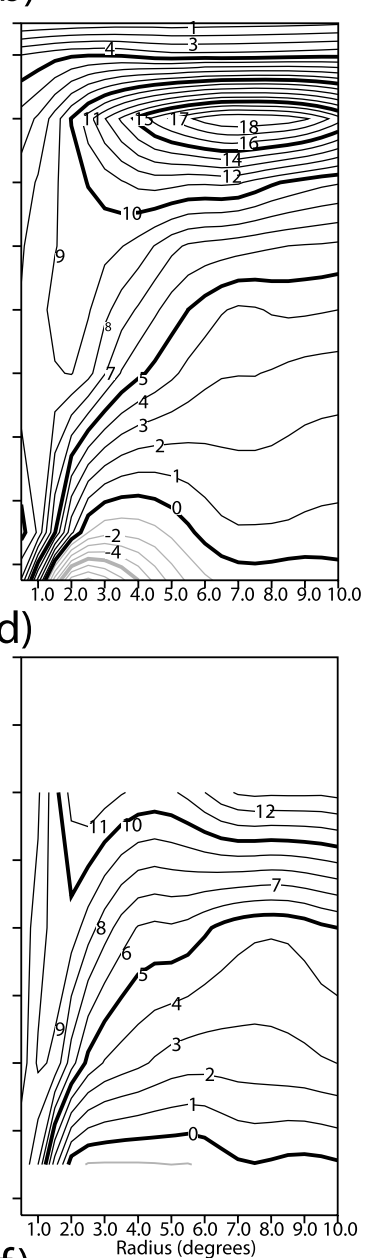

Fig. 3. Cross sections of tangential and radial wind component composites for the 100 most intense storms for each of the resolutions used, T63,

T213 and T319, (a) west to east, T63 tangential component, (b) south to north, T63 radial component, (c) west to east, T213 tangential component, (d) south to north, T213 radial component, (e) west to east, T319 tangential component and (f) south to north, T319 radial component. Wind speeds in $\mathrm{m} \mathrm{s}^{-1}$, bold line every $10 \mathrm{~m} \mathrm{~s}^{-1}$ for tangential winds and every $5 \mathrm{~m} \mathrm{~s}^{-1}$ for radial winds, negative values are in grey. 
at low levels in the boundary layer and outflow aloft, this again becoming more pronounced with resolution.

Finally, we consider the temperature anomaly and vorticity. These are more symmetric in nature so we show only the azimuthal averages for each resolution in Fig. 4. These show a marked warm core above $500 \mathrm{hPa}$ but with the warm anomaly extending to lower levels. Again this is consistent with observations (Frank, 1977). It is apparent from Fig. 4 that there is a substantial increase in the temperature anomaly with resolution from $\sim 2.5 \mathrm{~K}$ at $300 \mathrm{hPa}$ for $\mathrm{T} 63$ to $\sim 8 \mathrm{~K}$ for T319. A similar picture is obtained from the vorticity (Fig. 4) which shows a decrease in the size of the core and a general increase in the vorticity values with resolution. The correlation between the vertical vorticity gradient and the temperature anomaly is also apparent.

These results highlight that the ECHAM5 model at sufficient resolution can simulate the structure of TC remarkably well even from the composites of 100 storms and that given sufficient higher resolutions even more realistic storms might be generated. What is also apparent is the limitations of modelling and identifying TC in the T63 integrations.

\section{Climate change results for the T63 experiments}

The distribution of TC as a function of their maximum attained vorticity is shown in Fig. 5, and the total numbers in Table 2. There is a systematic difference between the three periods where the 19th century period has the largest number of TC and the 21 st century the smallest number. We have indicated the maximum and minimum between the three ensemble members with shading, that suggests that the decrease of the number of TC in the 20th century is not significant with a reduction of $1 \%$ and within the range of natural variability, while the decrease from the 20th to the 21 st century is highly significant with a reduction by $23 \%$. Comparing all nine combinations of $30 \mathrm{yr}$ duration between the 20th and the 21 st century gives reductions between 21 and $28 \%$. This is a slightly smaller reduction than in the studies by Bengtsson et al. (1996) and Sugi et al. (2002) but larger than the reduction found by Yoshimura et al. (2006). However, this will to some extent depend on the selection criteria. A similar reduction can be seen if we use a condition on the wind speed and only consider TC with maximum attained wind speeds greater than $18 \mathrm{~m} \mathrm{~s}^{-1}$ as shown in Table 3. As also can be seen from Fig. 5, Tables 2 and 3 there are no significant changes in the stronger cyclones.

The spatial distribution of the TC in the 20C and $21 \mathrm{C}$ experiments are shown in Fig. 6 as well as the difference 21C-20C. The significance of the difference is also shown and has been determined as described in Bengtsson et al. (2006) by MonteCarlo methods. For the genesis densities the genesis is taken as the point where the relative vorticity at $850 \mathrm{hPa}$ amounts to $0.5 \times 10^{-5} \mathrm{~s}^{-1}$. This is much weaker than the intensities for the TC identification and allows us to identify the storm pre- cursor and where storms really originate rather than when they are first considered a TC. The areas of genesis (Fig. 6a and b) are rather similar for both $20 \mathrm{C}$ and $21 \mathrm{C}$ with the highest densities in the eastern Pacific, probably associated with the more confined genesis region there. However, there is a noticeable reduction throughout the region for $21 \mathrm{C}$ and in particular in the eastern and western Pacific as indicated by the difference plot (Fig. 6c). The track densities (Fig. 6d and e) are also very similar in terms of their distribution with the strongest storm track in the Pacific extending to higher latitudes as storms move into the extratropics. The changes in the genesis density are reflected in the track density (Fig. 6f), which shows a distinct reduction in virtually all areas and in particular in the eastern and western Pacific.

In Fig. 7 we show the number of TC as a function of maximum wind speed. This shows that the reduction in numbers between $20 \mathrm{C}$ and $21 \mathrm{C}$ is mainly in the number of weak and moderate storms while the more intense ones have not changed in number consistent with the intensity distribution shown in Fig. 5. We have examined the tails of both distributions shown in Figs. 5 and 7 and have not been able to identify any difference in the intensity of the strongest storms.

We have also explored the conditions for TC generation. There are characteristic changes in the large-scale tropical circulation including a marked increase in the static stability as well as a reduced vertical circulation. There are also changes in the hydrological cycle including an increase in the residence time of water in the atmosphere supporting the reduced atmospheric circulation. We will return to these points in the discussion.

\section{Climate change results for the $\mathbf{T} 213$ experiments}

Due to computational restrictions we have only been able to undertake two $30 \mathrm{yr}$ integrations with the T213 resolution for the periods 1961-1990 and 2071-2100. Nor was it possible to run the fully coupled model at this resolution and we therefore used the SST boundary conditions (including its full time-space variability) from the T63 integration. The experiment follows the socalled time-slice approach (Bengtsson et al., 1996; IPCC 2001) and consequently this experiment cannot consider feedback with the oceans. However, the transient variation of greenhouse gases and sulphate aerosols is identical to the T63 run. The same is the case for the SST and sea ice, which is interpolated, from one of the T63 integrations. Fig. 8, shows the number of TC as a function of the vorticity maximum at $850 \mathrm{hPa}$ for the two periods. The number of TC [using the criteria $(6,6,4)$ ] is much higher in T213 compared to T63, almost by a factor of three (Table 1). The number of vortices identified depends both on the intensity at $850 \mathrm{hPa}$ but also on the vertical structure of the vortex suggesting that the low resolution version of the model has severe limitations in generating the typical warm core structure (see Section 3). 


\section{Temperature Anomaly}

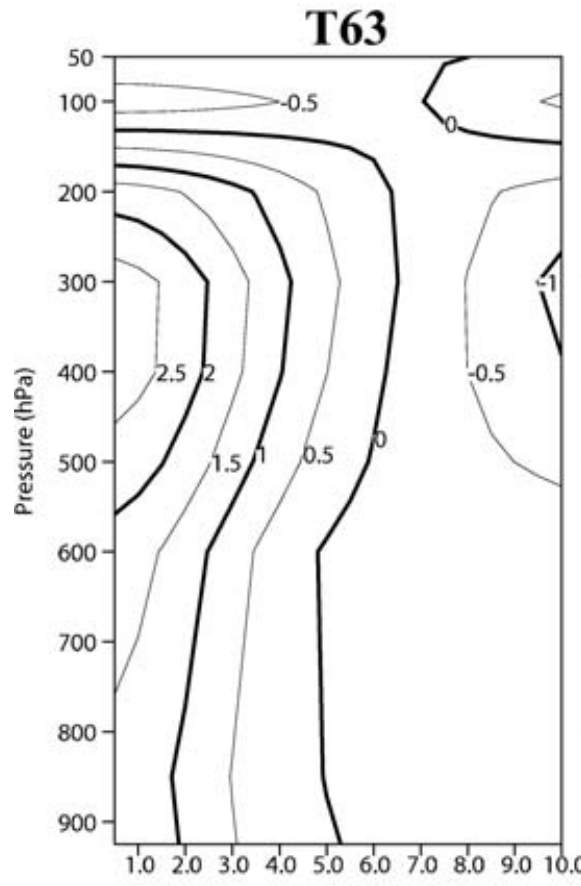

(a)
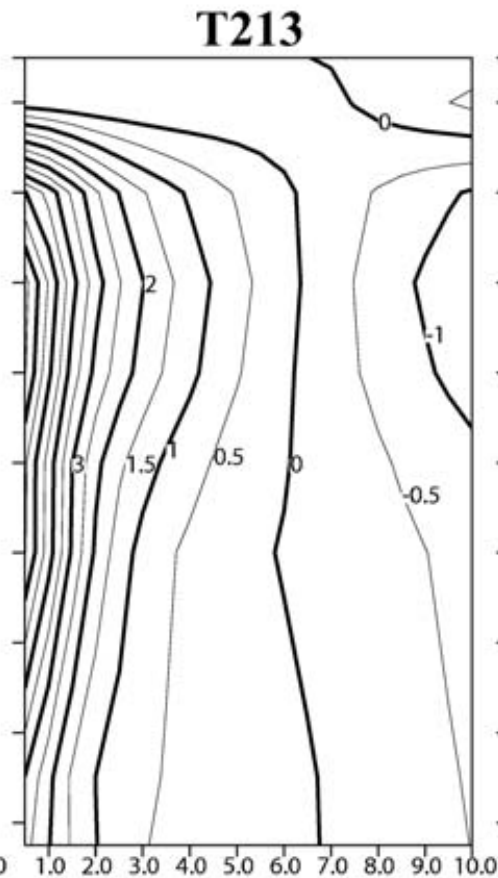

(b)
T319

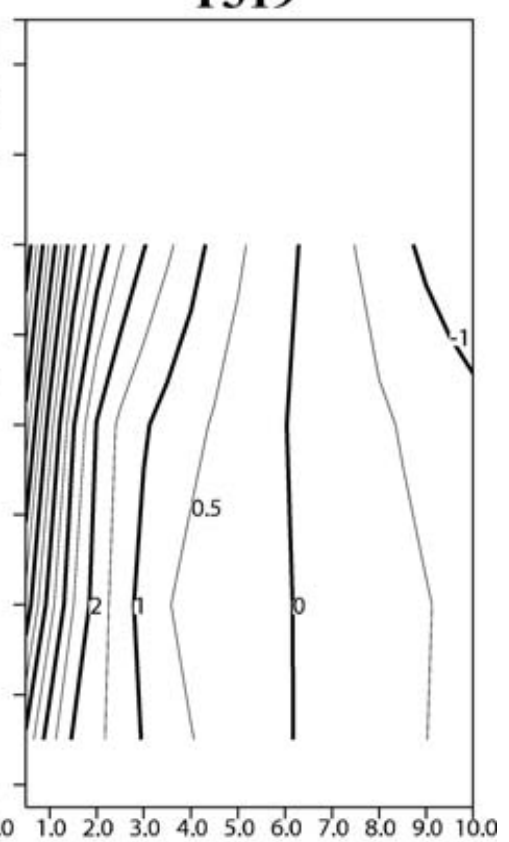

(c)

\section{Vorticity}

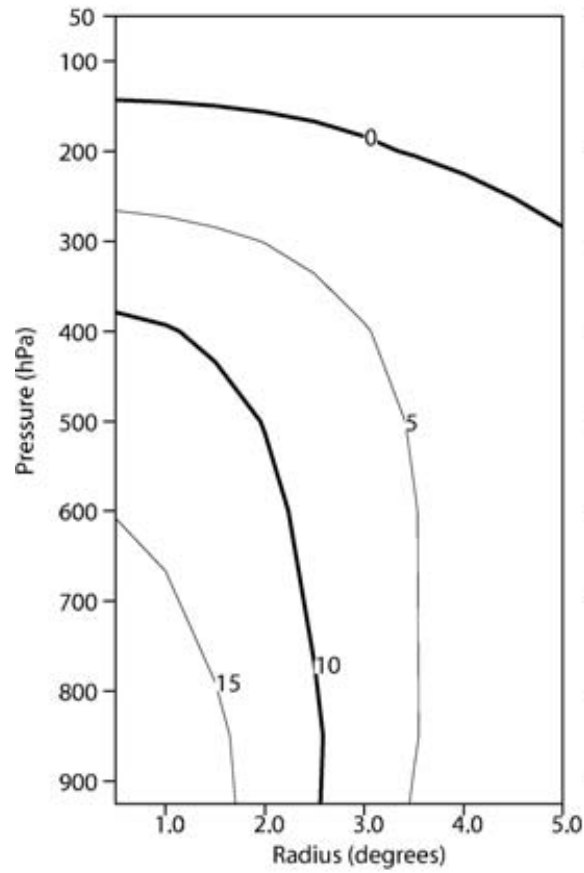

(d)

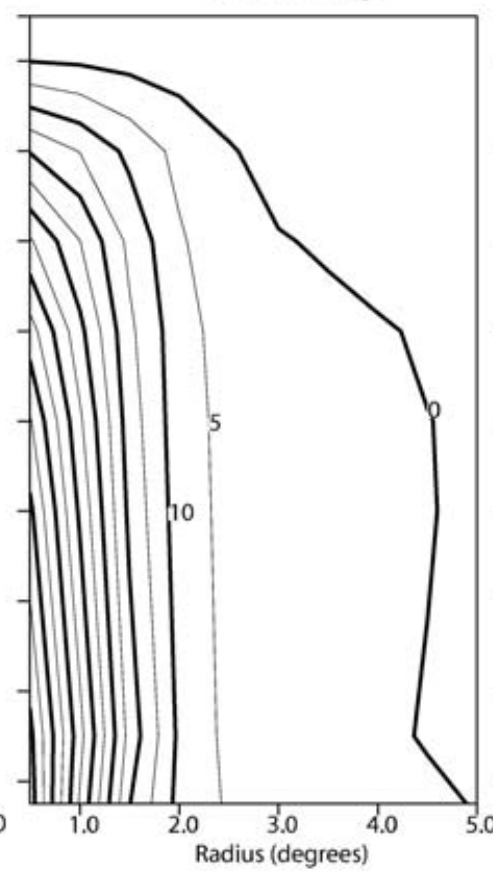

(e)

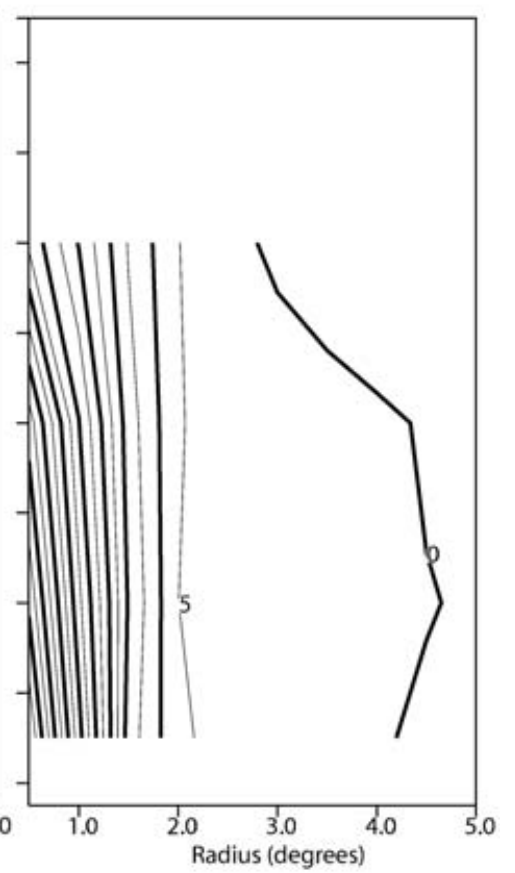

(f)

Fig. 4. Azimuthally averaged composites of temperature anomaly and vorticity for the 100 most intense storms for each of the resolutions used, T63, T213 and T319, (a) T63 temperature anomaly, (b) T213 temperature anomaly, (c) T319 temperature anomaly, (d) T63 relative vorticity, (e) $\mathrm{T} 213$ relative vorticity and (f) T319 relative vorticity. Temperature in units of $\mathrm{K}$, and vorticity in units of $10^{-5} \mathrm{~s}^{-1}$, respectively. Bold lines every $2 \mathrm{~K}$ for temperature and every $1 \times 10^{-4} \mathrm{~s}^{-1}$ for vorticity. 
Fig. 5. Number of TC per year in the $\mathrm{NH}$ as a function of maximum attained intensity based on $850 \mathrm{hPa}$ relative vorticity from the T63 experiments. Bin widths are $3 \times$ $10^{-5} \mathrm{~s}^{-1}$. Solid lines show the averages over the three ensemble members and the shading shows the spread for 19C (grey), 20C (red) and $21 \mathrm{C}$ (blue).

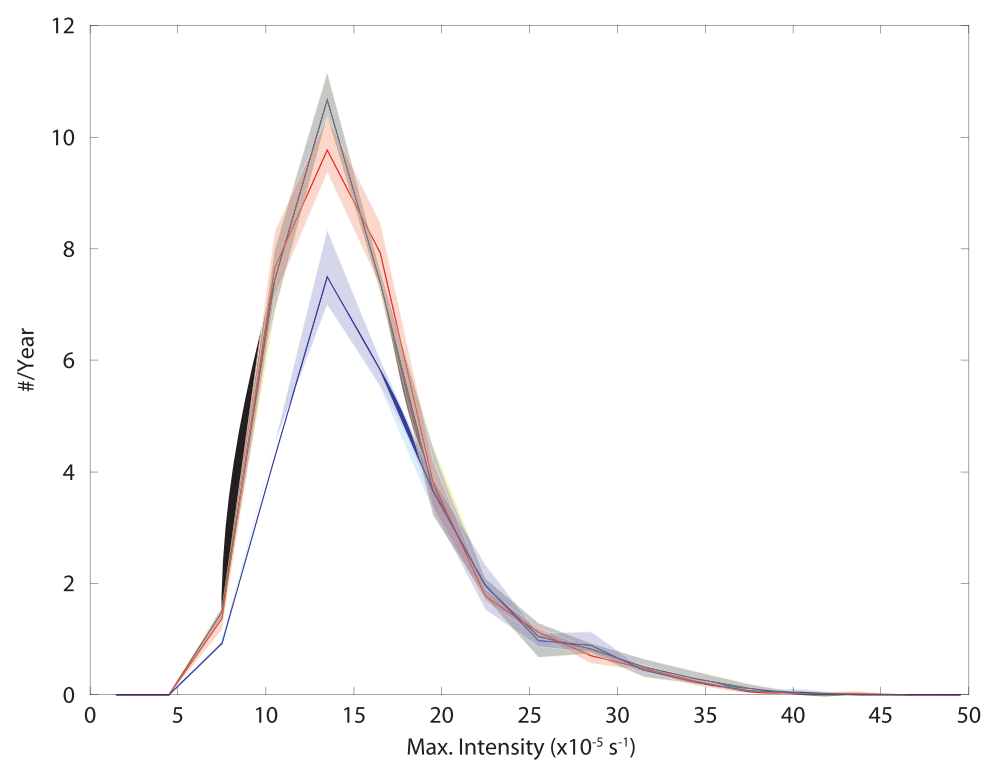

Table 2. Summary of the number of TC per year whose maximum intensity exceed some chosen values in terms of vorticity at $850 \mathrm{hPa}$ for T63 averaged over the three ensemble members

\begin{tabular}{lcccc}
\hline T63 & All $(6,6,4)$ & $>2 \times 10^{-4} \mathrm{~s}^{-1}$ & $>5 \times 10^{-4} \mathrm{~s}^{-1}$ & $>1 \times 10^{-3} \mathrm{~s}^{-1}$ \\
\hline $19 \mathrm{C}(1861-1890)$ & 35 & 5.8 & 0 & 0 \\
$20 \mathrm{C}(1961-1990)$ & 33 & 5.4 & 0 & 0 \\
$21 \mathrm{C}(2071-2100)$ & 25 & 5.5 & 0 & 0 \\
\hline
\end{tabular}

Table 3. Summary of the number of TC per year whose maximum wind speed at $925 \mathrm{hPa}$ exceeds certain values for T63 averaged over the three ensemble members

\begin{tabular}{lccc}
\hline T63 & $>18 \mathrm{~m} \mathrm{~s}^{-1}$ & $>33 \mathrm{~m} \mathrm{~s}^{-1}$ & $>50 \mathrm{~m} \mathrm{~s}^{-1}$ \\
\hline 19C (1861-1890) & 34 & 6.3 & 0.2 \\
20C (1961-1990) & 32 & 6.0 & 0.1 \\
$21 \mathrm{C}(2071-2100)$ & 25 & 6.2 & 0.1 \\
\hline
\end{tabular}

Like the T63 there is a reduction in the number of TC when going from the 20 th to the 21 st century, but the reduction is smaller and only $9 \%$ as shown in Table 4 . However, the largest difference from T63 is the increase in the more intense TC for 21C. In fact, there are more than $60 \%$ more intense storms (based on $850 \mathrm{hPa}$ vorticity $>10^{-3} \mathrm{~s}^{-1}$ ) in $21 \mathrm{C}$ than in $20 \mathrm{C}$. A similar intensification can also be seen in minimum surface pressure and in maximum wind speed (Fig. 9, Table 5). The number of storms, with maximum wind speed above $50 \mathrm{~m} \mathrm{~s}^{-1}$, increases by some $30 \%$. In this respect the result is similar to Oouchi et al. (2006). There are several explanations for this, which we intend to develop more in the discussion. The most likely explanation is that a high horizontal resolution is necessary to satisfactorily describe the convergence of momentum in order to generate strong enough vertical motions to release latent heat effectively.
The likely explanation for the intensification for $21 \mathrm{C}$ is the large increase in atmospheric water vapour, which is broadly related to temperature following the Clausius-Clapeyron relation.

The patterns of cyclogenesis, shown in Fig. 10a and b, though showing some similarities to T63 also shows several differences. The concentration of cyclogenesis is weaker than in T63, in the eastern Pacific but extends further back into Central America; in the western Pacific cyclogenesis is also weaker but shows higher values in the central Pacific, whilst in the Atlantic the density shows higher values extending back into the western African region. Note, the fact that the density may look weaker in several areas in $\mathrm{T} 213$ does not mean there are fewer systems in total than in T63 but that the cyclogenesis is more diffuse. We suggest the explanation for these differences is our definition of an initial vortex in the model to be as small as $5 \times 10^{-6} \mathrm{~s}^{-1}$. This is likely to be much less than the first indication of a tropical vortex as would be determined by an operational meteorologist, which means that weaker onset vortices are being generated further to the east in the Pacific and over Africa and undergo a weak amplification during the first period as they move westward (Bengtsson et al., 2007). This combined with the higher resolution of T213 means we are identifying the TC even earlier in their lifecycle than in T63. In terms of the change in the distributions between $20 \mathrm{C}$ and $21 \mathrm{C}$ (Fig. 10c), there are subregions of marked increase and decrease in cyclogenesis for $21^{\circ} \mathrm{C}$ in the eastern Pacific contrary to T63 


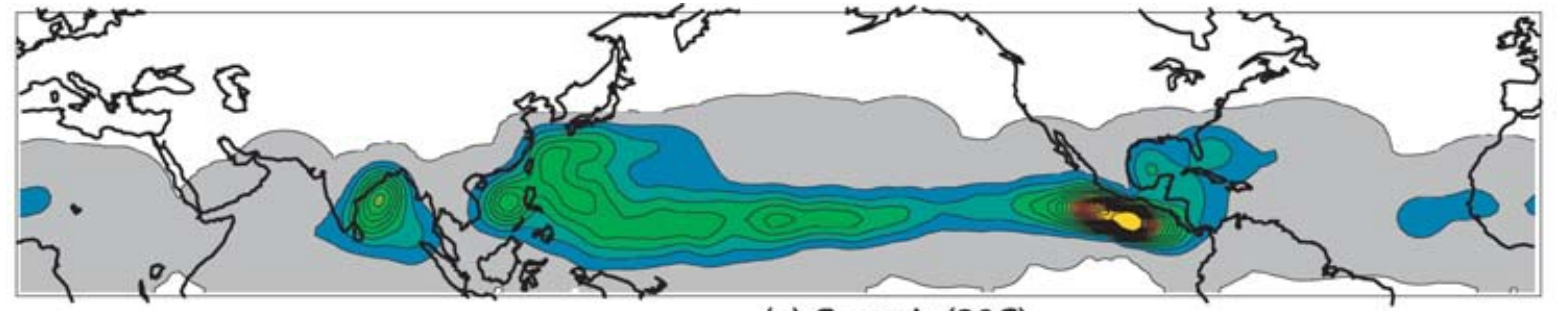

(a) Genesis (20C)
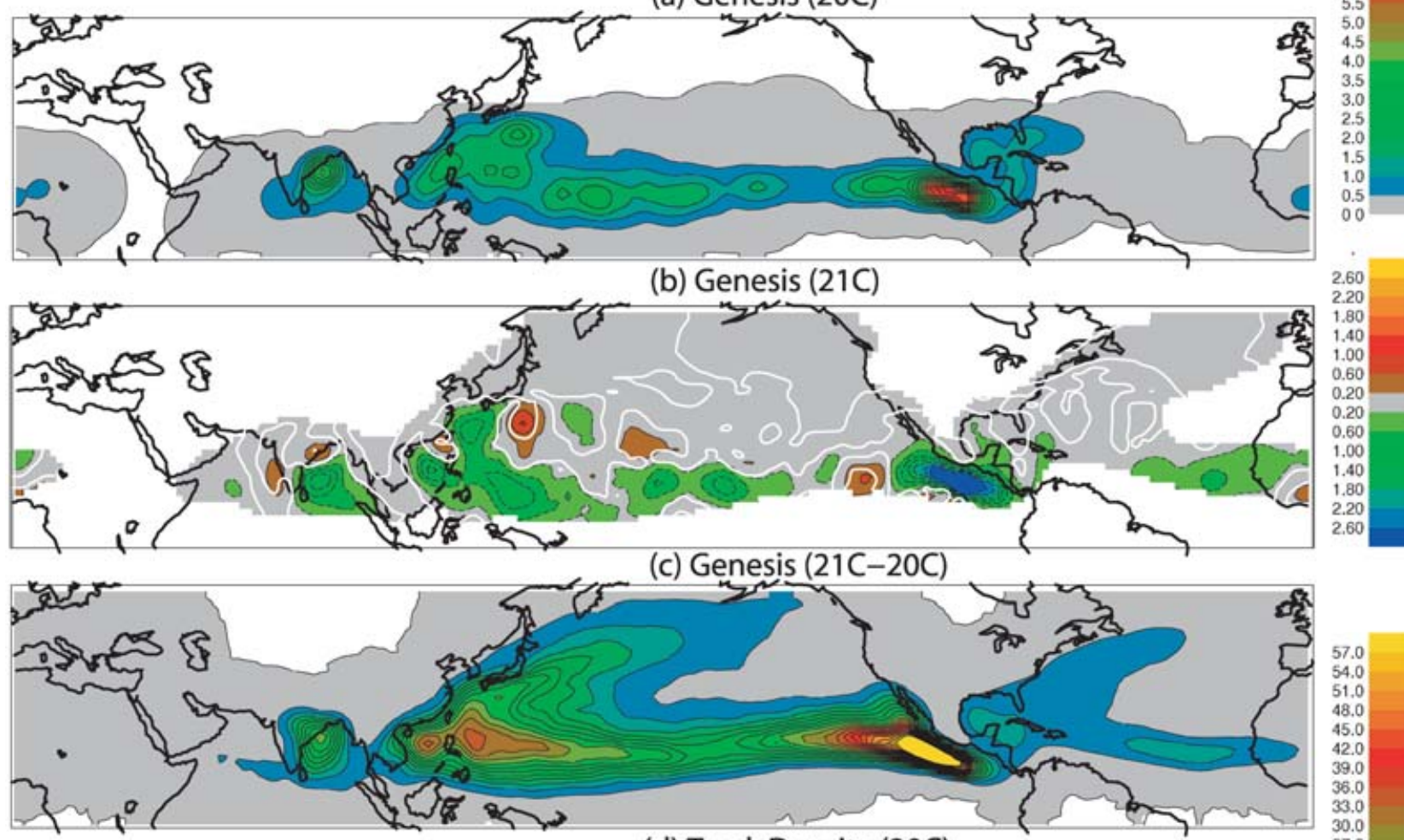

(d) Track Density (20C)
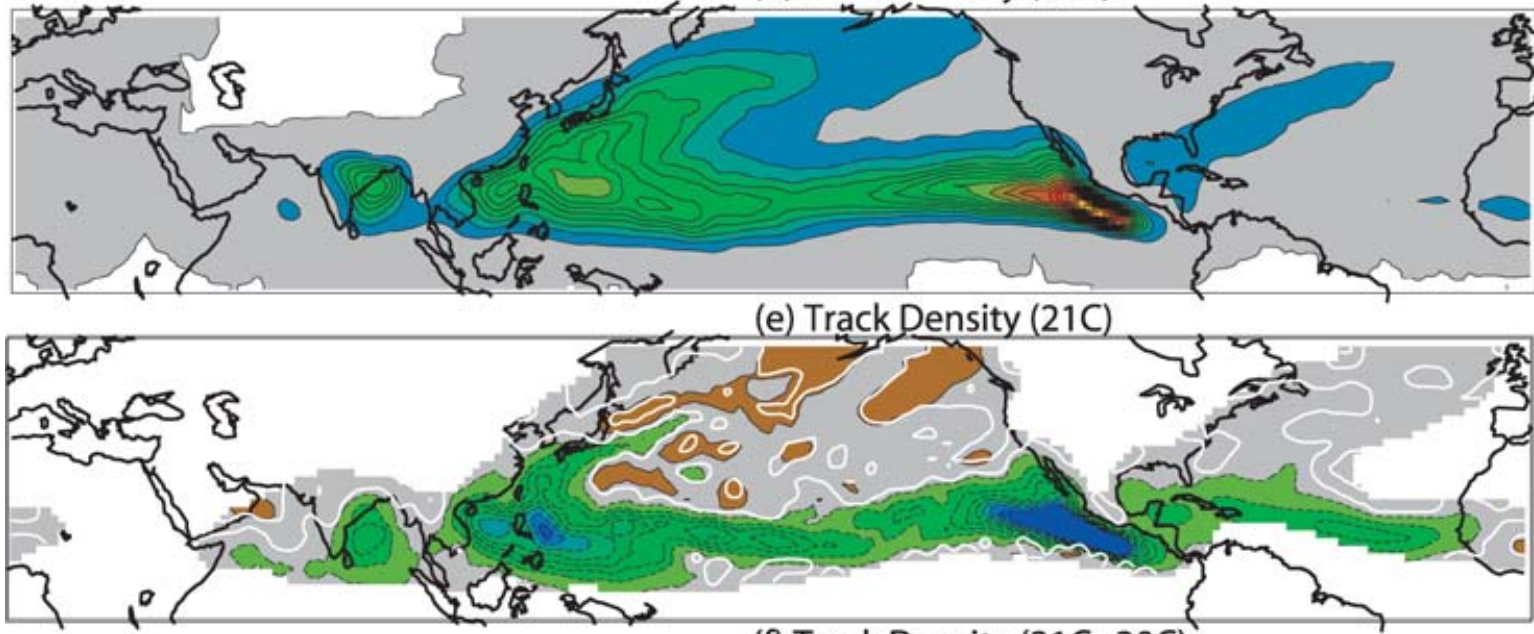

(f) Track Density (21C-20C)

Fig. 6. Genesis and track densities for 20C and 21C for T63 averaged over the three ensemble members, (a) 20C genesis, (b) 21C genesis, (c) 21C-20C genesis, (d) 20C track density, (e) $21 \mathrm{C}$ track density and (f) $21 \mathrm{C}-20 \mathrm{C}$ track density. Densities are in units of number density per year per unit area, where the unit area is equivalent to a $5^{\circ}$ spherical cap $\left(\sim 10^{6} \mathrm{~km}^{2}\right)$. Differences have been suppressed where the track density is below 0.5 . White lines indicate the region boundaries of significance at $95 \%$. 


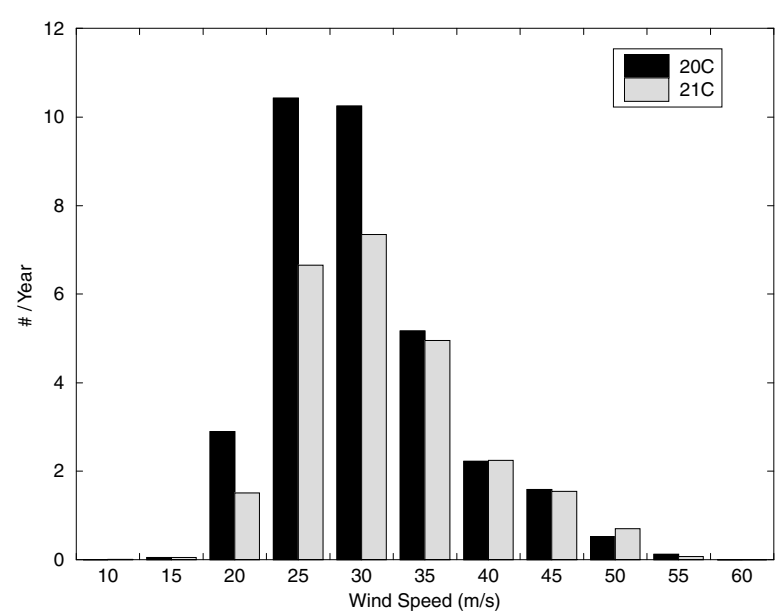

Fig. 7. Distribution of maximum wind speeds for NH, TC at $925 \mathrm{hPa}$ for $20 \mathrm{C}$ and $21 \mathrm{C}$ for T63. Bin widths are $5 \mathrm{~m} \mathrm{~s}^{-1}$.

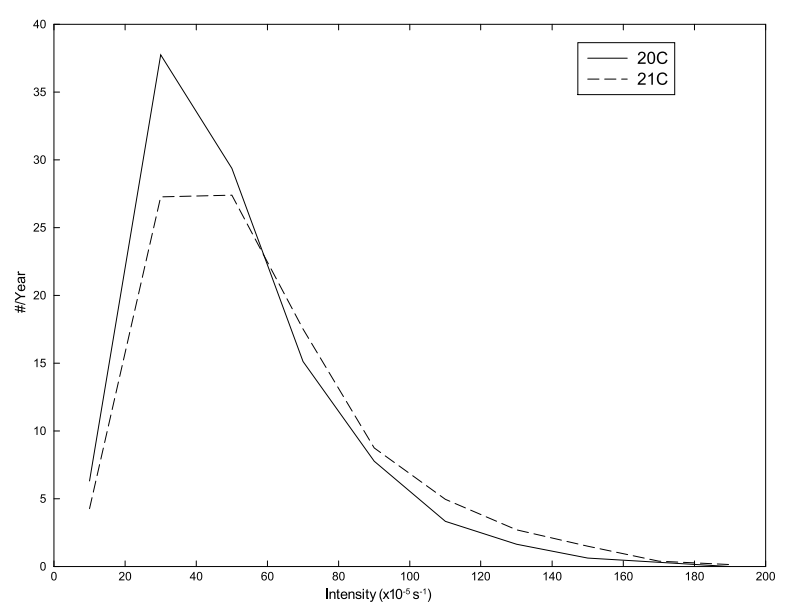

Fig. 8. T213 distributions of maximum attained intensity for NH, TC based on $850 \mathrm{hPa}$ relative vorticity for $20 \mathrm{C}$ and $21 \mathrm{C}$. Bin widths are $2 \times 10^{-4} \mathrm{~s}^{-1}$.

where there is only a reduction. This may be a resolution issue as the region of cyclogenesis in the eastern Pacific is restricted and influenced by orography and coast lines which are only poorly resolved in T63. In the central and western Pacific there is a general decrease between $20 \mathrm{C}$ and $21 \mathrm{C}$ in agreement with T63. However, in the Atlantic whilst there is a weak decrease there is an increase in the genesis over western Africa.

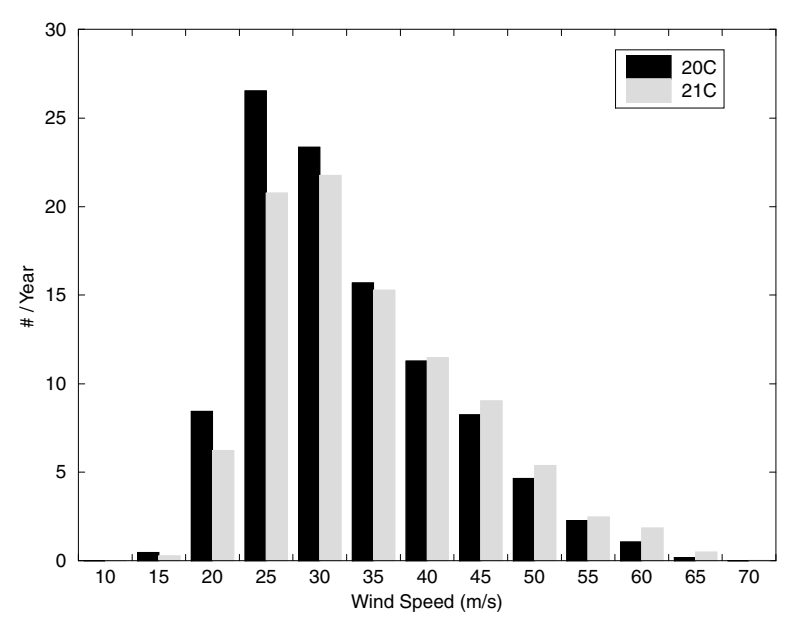

Fig. 9. Distribution of maximum wind speeds for $\mathrm{NH}, \mathrm{TC}$ at $925 \mathrm{hPa}$ for $20 \mathrm{C}$ and $21 \mathrm{C}$ for T213. Bin widths are $5 \mathrm{~m} \mathrm{~s}^{-1}$.

Table 5. Summary of the number of TC per year whose maximum wind speed at $925 \mathrm{hPa}$ exceed certain values, for T213

\begin{tabular}{lccc}
\hline T213 & $>18 \mathrm{~m} \mathrm{~s}^{-1}$ & $>33 \mathrm{~m} \mathrm{~s}^{-1}$ & $>50 \mathrm{~m} \mathrm{~s}^{-1}$ \\
\hline $20 \mathrm{C}(1961-1990)$ & 100 & 33 & 3.7 \\
$21 \mathrm{C}(2071-2100)$ & 92 & 36 & 4.9 \\
\hline
\end{tabular}

The track density for 20C and 21C for T213 are shown in Fig. 10d and e. In addition to an overall increase in the track density for T213 compared with T63, due to the larger number of TC, there is a marked difference in the storm track into the central Pacific from the genesis region in the eastern Pacific. We suggest this is primarily due to high SST and reduced wind shear in the region. The reason that this does not happen in the T63 experiment is the inability of the coarse resolution model to resolve the intense genesis region in the eastern Pacific. The difference between 20C and 21C (Fig. 10f) also show differences from T63 with an apparent shift southwards of the eastern Pacific storm track and a general reduction through the rest of the tropical Pacific whereas in T63 there is a reduction everywhere. However, the pattern of difference seen in the Pacific in T213 does have similarities with that shown in Bengtsson et al. (2006) which included all tropical transient vorticies, not just TC, suggesting that the main difference in the response between $20 \mathrm{C}$ and $21 \mathrm{C}$ between T63 and T213 is due to the TC selection criteria. As shown

Table 4. Summary of the number of TC per year whose maximum intensity in terms of vorticity at $850 \mathrm{hPa}$ exceed certain values, for $\mathrm{T} 213$

\begin{tabular}{lcccc}
\hline T213 & All $(6,6,4)$ & $>2 \times 10^{-4} \mathrm{~s}^{-1}$ & $>5 \times 10^{-4} \mathrm{~s}^{-1}$ & $>1 \times 10^{-3} \mathrm{~s}^{-1}$ \\
\hline $20 \mathrm{C}(1961-1990)$ & 104 & 97 & 40 & 6.0 \\
$21 \mathrm{C}(2071-2100)$ & 94 & 90 & 49 & 9.8 \\
\hline
\end{tabular}



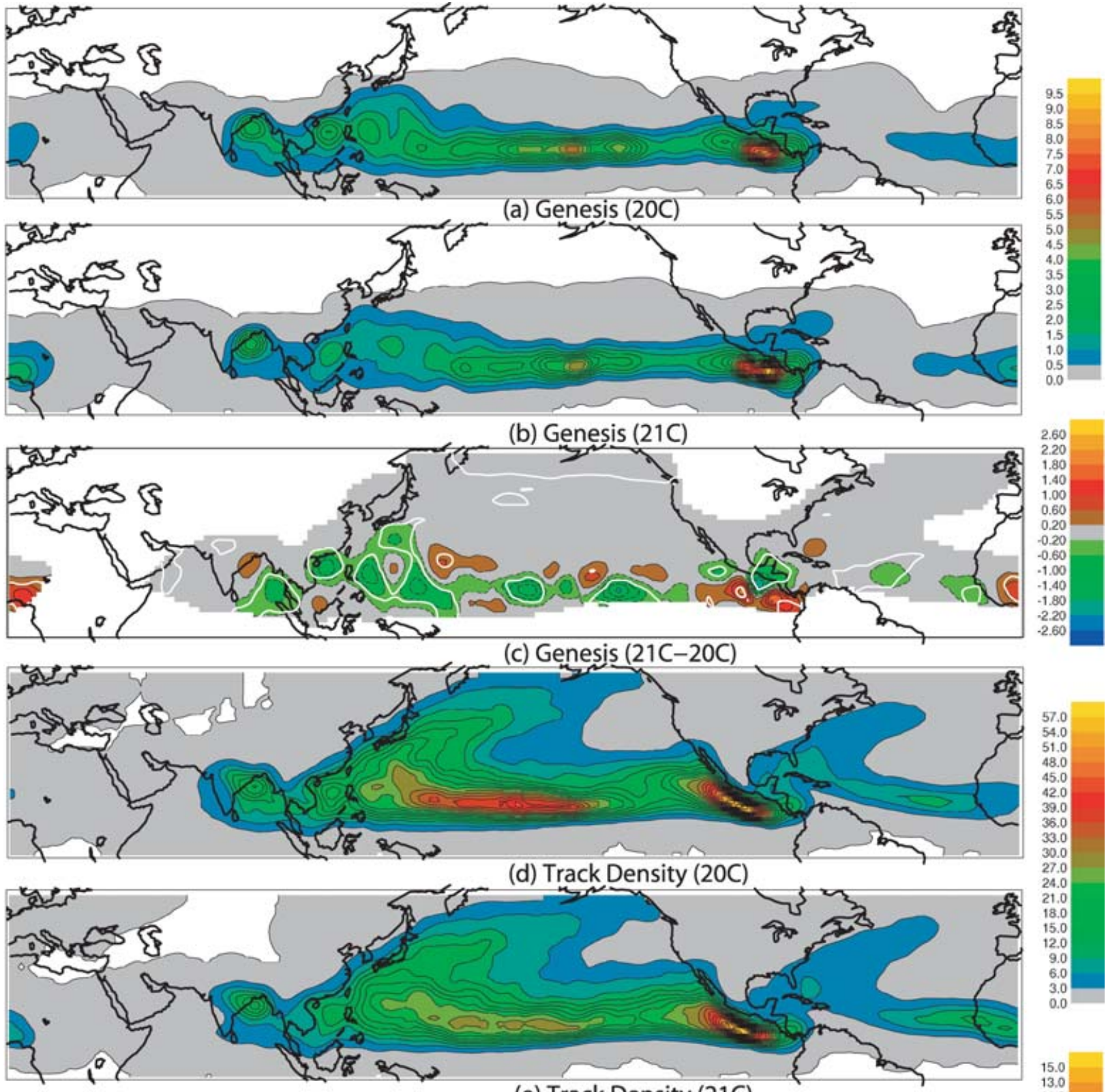

(f) Track Density (21C-20C)

Fig. 10. Genesis and track densities for 20C and 21C for T213, (a) 20C genesis, (b) 21 genesis, (c) 21C-20C genesis, (d) 20C track density, (e) 21C track density and (f) $21 \mathrm{C}-20 \mathrm{C}$ track density. Densities are in units of number density per year per unit area, where the unit area is equivalent to a $5^{\circ}$ spherical cap $\left(\sim 10^{6} \mathrm{~km}^{2}\right)$. Differences have been suppressed where the track density is below 0.5 . White lines indicate the region boundaries of significance at $95 \%$. 
in Bengtsson et al. (2007) the TC have been calibrated against operational analyses which are integrated at similar resolutions to the T213. In the Atlantic sector there is a general reduction along the southerly storm track but an increase over Africa extending into the Atlantic. The part of the track over Africa is unlikely to be associated with the TC stage of the storms but highlights that several of the storms have their origins over the continent which shows a change from $20 \mathrm{C}$ to $21 \mathrm{C}$. The reason for this is not clear, in particular as the ECHAM5 model produces a different distribution of easterly wave type activity over Africa for the current climate and in AMIP integrations than is seen in re-analyses (Bengtsson et al., 2006). Another contributing factor is a systematic error in the SST of the coupled model along parts of the African coast where the temperature at $20 \mathrm{C}$ is about $2^{\circ} \mathrm{C}$ too high compared to observations (not shown). It is suggested that this is due to insufficient ocean upwelling or to a model deficiency in simulating stratus cloud there.

A more detailed view of the regional changes can be obtained by isolating TC for particular regions (shown in Fig. 11). These are shown in Fig. 12 in terms of the number versus maximum

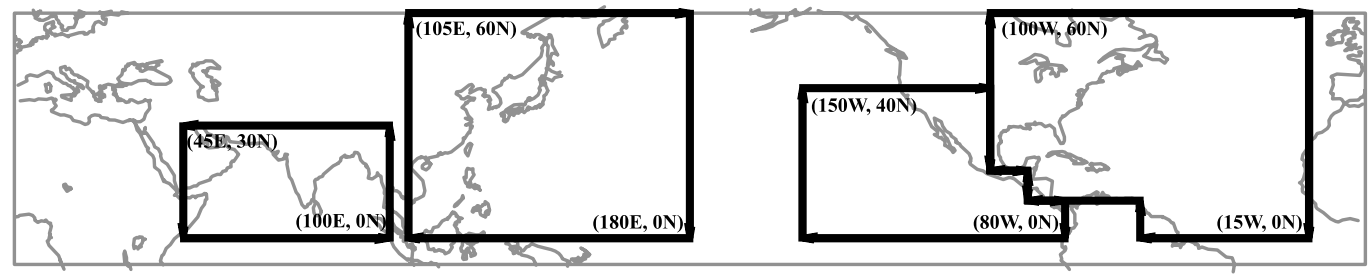

Fig. 11. Areas for TC subsetting based on maximum intensity.
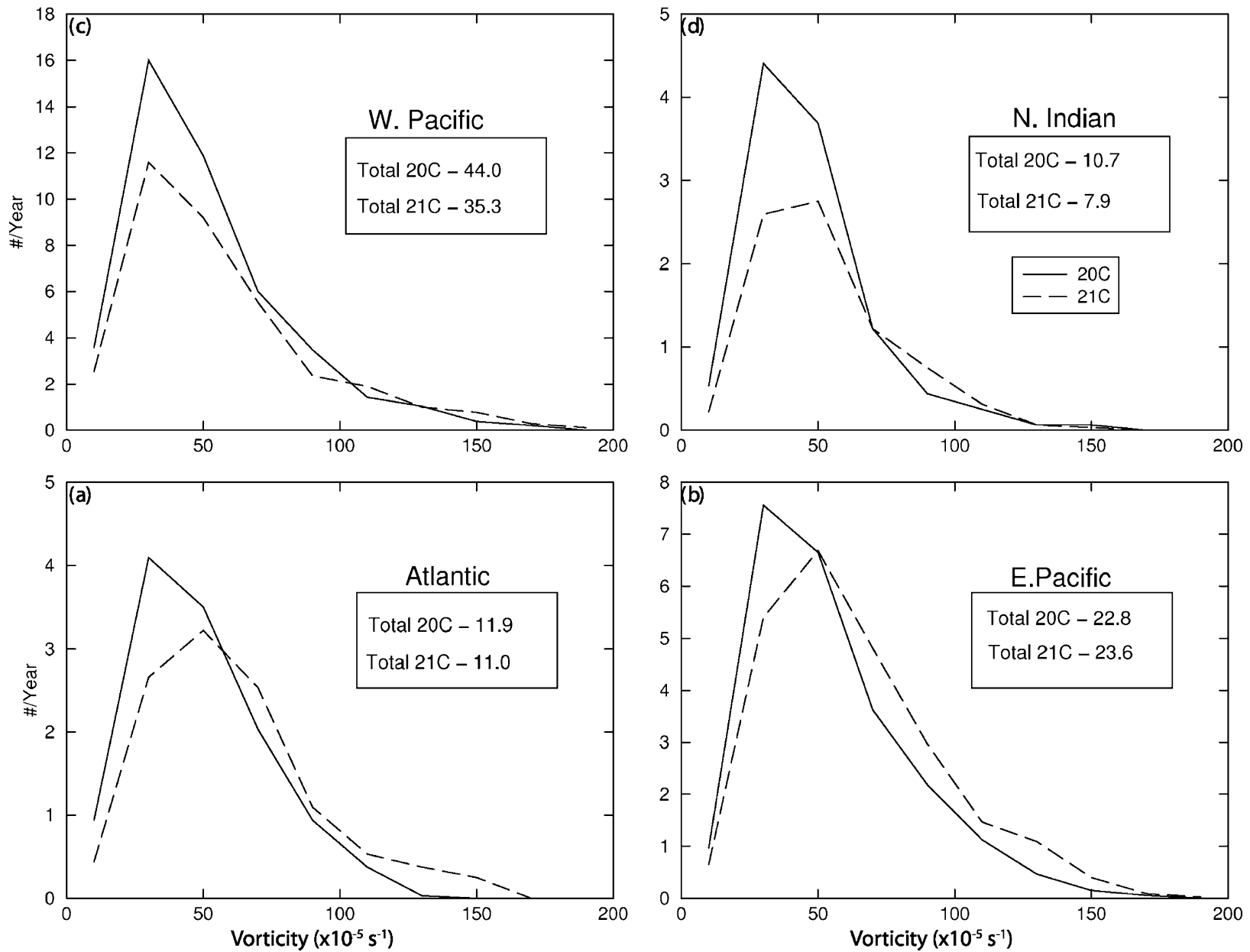

Fig. 12. T213 regional distributions of maximum attained intensity based on $850 \mathrm{hPa}$ relative vorticity for $20 \mathrm{C}$ and $21 \mathrm{C}$ for (a) Atlantic, (b) eastern Pacific, (c) western Pacific and (d) north Indian ocean. Bin widths are $2 \times 10^{-4} \mathrm{~s}^{-1}$. Inset boxes show the total number per year for each region and for $20 \mathrm{C}$ and $21 \mathrm{C}$, respectively. 
intensity distributions, based on vorticity, and show interesting differences. The TC are assigned to the region where they obtain their maximum intensity. A reduction in the weak and medium cyclones occurs in all regions as well as an intensification of the stronger cyclones. The largest intensification takes place in the eastern Pacific and in the Atlantic. Note that the total number of TC are slightly less than shown in Table 4 as some storms, mainly weaker ones may reach their maximum intensity outside the regions shown in Fig. 11.

There are no major changes in the annual variability (Fig. 13a), between $20 \mathrm{C}$ and $21 \mathrm{C}$, except a larger proportional reduction of TC outside the active season for T213. Here one may have expected the opposite since the higher SST would have favoured an increased number of cyclones in other seasons. In T63 there is a reduction of TC throughout the year (Fig. 13a). The interannual variability is somewhat higher in $20 \mathrm{C}$ than in $21 \mathrm{C}$ when we consider all TC (Fig. 13b) but becomes more similar for the two periods when we restrict the TC to those with maximum wind speeds greater than $33 \mathrm{~m} \mathrm{~s}^{-1}$ (Fig. 13c) showing that the higher variability in $20 \mathrm{C}$ is due to interannual variations of the weaker storms. For TC above $33 \mathrm{~m} \mathrm{~s}^{-1}$ the standard deviation is about $15 \%$, or close to the observed value.

We have calculated the PDI (Emanuel, 2005) for all the TC in $20 \mathrm{C}$ and $21 \mathrm{C}$ (not shown), for that part of their tracks which satisfy our criteria for a TC. There are considerable variations from year-to-year, which hardly make it possible to calculate reliable trends. Comparing the PDI of the total number of TC (all TC satisfying the $(6,6,4)$ criteria at $20 \mathrm{C}$ and $21 \mathrm{C}$ there is a minor increase of $6 \%$. Another calculation restricting it to TC with wind speed above $33 \mathrm{~m} \mathrm{~s}^{-1}$ shows increases of the PDI by $16 \%$. This increase is due to intensification of the most powerful storms but also to a minor increase in the lifetime of TC at $21 \mathrm{C}$ (not shown).

\section{Changes in the hydrological cycle and its consequences}

We analyse here the changes in the hydrological cycle but will concentrate the discussion on the T213 experiment. Results of the changes in the hydrological cycle averaged for the globe and for the tropics, respectively, are summarized in Table 6 . We give here the values for T213 but the values for T63 differ only by $1-2 \%$ for evaporation and precipitation and less than $1 \%$ for column water vapour.

The result is typical for a climate change experiment with a modest increase in evaporation and precipitation which for this model is $\sim 6 \%$. At the same time there is a major increase in the total amount of atmospheric water vapour by $26 \%$ (27\% for the tropics). The increase in total water vapour follows closely the Clausius-Clapeyron relation, as this model like most other models practically conserves relative humidity (Held and Soden, 2006). The fact that atmospheric water vapour increases faster than precipitation between $20 \mathrm{C}$ and $21 \mathrm{C}$, implies an increase in
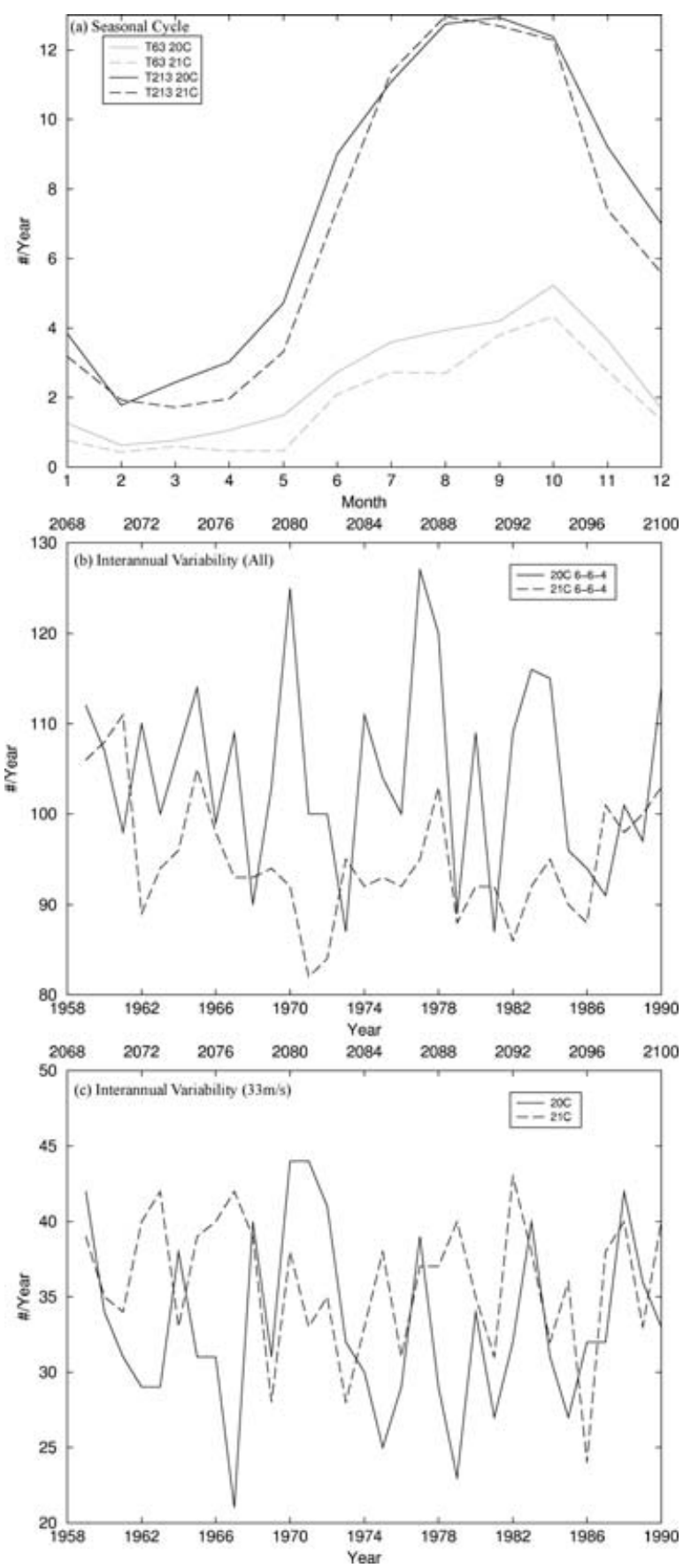

Fig. 13. (a) Seasonal cycle for $\mathrm{NH}, \mathrm{TC}$ for $\mathrm{T} 213$ and $\mathrm{T} 63$ for $20 \mathrm{C}$ and $21 \mathrm{C}$, (b) interannual variability for T213 for $20 \mathrm{C}$ and $21 \mathrm{C}$ and (c) same as (a) but for storms with maximum wind speeds greater than $33 \mathrm{~m} \mathrm{~s}^{-1}$.

the residence time of water in the atmosphere from 8.7 to $10.3 \mathrm{~d}$. The change in the residence time of water for the T63 model is similar with a change from 8.9 to $10.6 \mathrm{~d}$. For the T63 model the residence time for $19 \mathrm{C}$ is calculated to be $8.7 \mathrm{~d}$. The reason for the slower increase in global precipitation and thus in global evaporation is because evaporation is largely determined by the 
Table 6. Summary of changes in the hydrological cycle averaged for the globe and for the tropics

\begin{tabular}{lcccc}
\hline & 20C global & 21C global & 20C tropics & 21C tropics \\
\hline Precipitation $\left(\mathrm{mm} \mathrm{d}^{-1}\right)$ & 2.97 & 3.16 & 3.58 & 3.81 \\
Evaporation $\left(\mathrm{mm} \mathrm{d}^{-1}\right)$ & 2.96 & 3.14 & 4.12 & 4.41 \\
Column water vapour $\left(\mathrm{kg} \mathrm{m}^{-2}\right)$ & 25.71 & 32.50 & 37.65 & 47.97 \\
\hline
\end{tabular}

net radiative heat imbalance at the surface. This increase is less than the increase in water vapour. This behaviour, as we will return to in the discussion, is a contributing factor for the weakening of the tropical circulation and presumably a reason for the reduced number of TC in a warmer climate, Sugi et al. (2002). On the other hand when TC do develop under favourable dynamical conditions they are likely to draw on the increased level of atmospheric water vapour (and thus indirectly to the higher SST) and consequently become more intense.

We next investigate the amount of precipitation from the TC tracks. We calculate the area averaged precipitation from all gridpoints within a circular geodesic area with an arc radius of $5^{\circ}$ centred on the storm centre, and accumulate this along the track from each 6 hourly position. This area is large $\left(\sim 10^{6} \mathrm{~km}^{2}\right)$ but the circulation pattern around a major tropical cyclone covers almost an area of this size. The result is summarized in Fig. 14a, where we show the area averaged precipitation, accumulated along the tracks, in $50 \mathrm{~mm}$ bins for that part of the TC tracks that satisfy the criteria $\xi_{\text {int }} \geq 6 \times 10^{-5} \mathrm{~s}^{-1}$ and $\xi_{\text {diff }} \geq 6 \times 10^{-5} \mathrm{~s}^{-1}$. In the $20 \mathrm{C}$ integration there are 2 tracks per year with an accumulated average precipitation of between 450 and $500 \mathrm{~mm}$. There is a marked change in going to $21 \mathrm{C}$. The average precipitation per track increases from 164 to $199 \mathrm{~mm}$ or by $21 \%$ with the largest increase in the more intense events. However, the total increase in precipitation of the TC increases less as the number of storms is fewer in $21 \mathrm{C}$ than in $20 \mathrm{C}$. We have also calculated the results for the more intense storm tracks which reach wind speeds of $33 \mathrm{~m} \mathrm{~s}^{-1}$ (Fig. 14b). The average precipitation for these tracks increases from $253 \mathrm{~mm}$ to $301 \mathrm{~mm}$. In this case the number of storms in this category increases in $21 \mathrm{C}$ providing an overall precipitation increase of $30 \%$.

It is interesting to note the significant contribution from TC to the global hydrological cycle and to the energy balance of the atmosphere. The overall annual contribution to the Northern Hemisphere precipitation is some $6 \%$ and to the warming of the atmosphere, through latent heat flux, some $5 \mathrm{~W} \mathrm{~m}^{-2}$.

\section{Consequences of a further increase in horizontal resolution}

To support the findings of this study we have examined a further time-slice numerical experiment at T319 resolution by the ECHAM5 model. This experiment was undertaken similar to
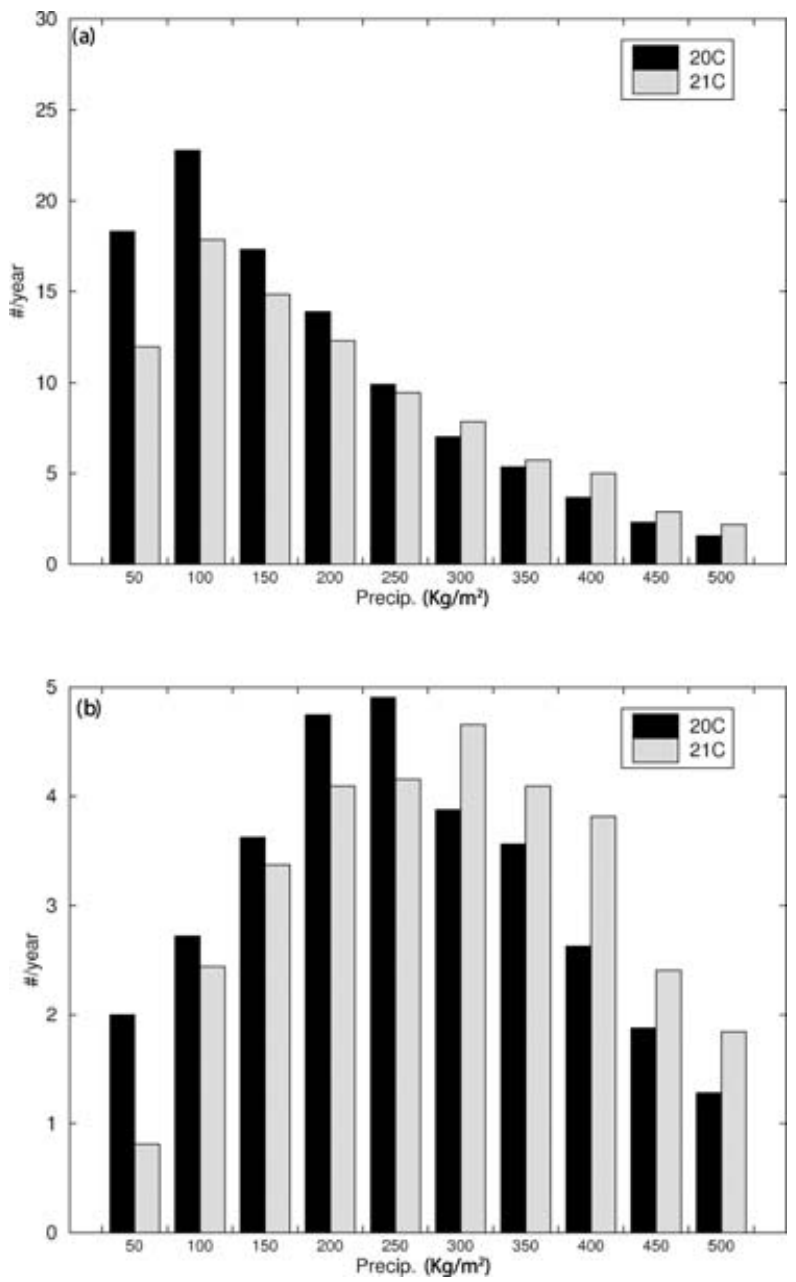

Fig. 14. Distributions for average precipitation along NH, TC tracks, averaged over the part of the tracks that satisfy the TC identification criteria of $\xi_{\text {int }} \geq 6 \times 10^{-5} \mathrm{~s}^{-1}$ and $\xi_{\text {diff }} \geq 6 \times 10^{-5} \mathrm{~s}^{-1}$, (a) all TC and (b) TC which attain a maximum wind speed of $33 \mathrm{~m} \mathrm{~s}^{-1}$. Bin widths are $50 \mathrm{~kg} \mathrm{~m}^{-2}$.

the T213 experiment but with a slightly shorter integration time covering two 20 year periods of 1980-2000 and 2080-2100, respectively. Due to storage difficulties the number of vertical levels have been restricted to $850,700,500$ and $300 \mathrm{hPa}$, respectively. Like the T213 experiment the SST are from the T63 coupled model. 

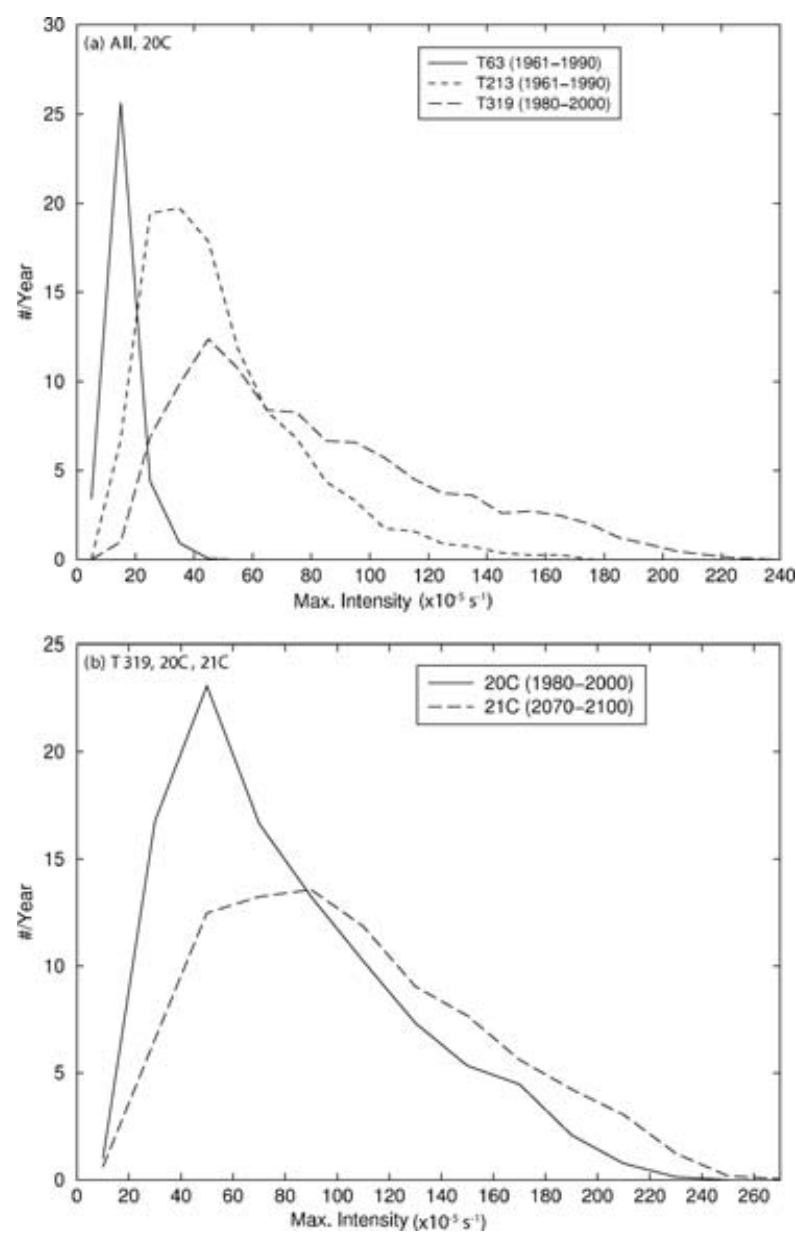

Fig. 15. Maximum attained intensity distributions for $\mathrm{NH}$, TC based on the $850 \mathrm{hPa}$ relative vorticity for (a) all resolutions, T63, T213 and T319, bin widths $1.0 \times 10^{-4} \mathrm{~s}^{-1}$, (b) T319, 20C and 21C, bin widths $2.0 \times 10^{-4} \mathrm{~s}^{-1}$.

Figure 15a compares the annual number of TC for the three different resolutions T63, T213 and T319 at 20C. The T63 and T213 are for the period 1961-1990 but T319 for the period 1980-2000. As shown in Tables 2 and 4 the number of TC per year in T63 is about a third of that of T213 but as can be seen from Tables 7 and 8 the number in T319 is practically the same as in T213. We have also examined the number of TC in T159 (Bengtsson et al., 2007), not shown, and noted that the number is about the same as it is for T213 and T319. However, while the number of TC
Table 8. Summary of the number of TC per year whose maximum wind speed at $850 \mathrm{hPa}$ exceed certain values, for T319

\begin{tabular}{lccc}
\hline T319 & $>18 \mathrm{~m} \mathrm{~s}^{-1}$ & $>33 \mathrm{~m} \mathrm{~s}^{-1}$ & $>50 \mathrm{~m} \mathrm{~s}^{-1}$ \\
\hline $20 \mathrm{C}(1961-1990)$ & 97 & 44 & 12 \\
$21 \mathrm{C}(2071-2100)$ & 87 & 51 & 17 \\
\hline
\end{tabular}

in the higher resolution is the same the distribution as a function of maximum vorticity is gradually changed towards a smaller scale and higher intensity as the resolution increases from T63 to T319. Using the distance between the centre of the storm and the point of maximum wind speed as a measure of the dimension of the storm this distance is reduced from $340 \mathrm{~km}$ for the T63 to $130 \mathrm{~km}$ for the T319. See also the presentation in Section 3 on the structure of the storms. The maximum wind speed at T319 (at $850 \mathrm{hPa}$ ) is $80.7 \mathrm{~m} \mathrm{~s}^{-1}$ at $20 \mathrm{C}$ and it is increased to $86.8 \mathrm{~m} \mathrm{~s}^{-1}$ at $21 \mathrm{C}$.

The change from $20 \mathrm{C}$ to $21 \mathrm{C}$ in $\mathrm{T} 319$, shown in Fig. 15b, is similar to the results in T213 with a reduced number of TC but more intense ones. We show here the maximum vorticity for the two periods, but the result is similar for the maximum wind speed. Areas of genesis and track density (not shown) are also similar to T213 but with a slightly larger change towards a more eastern and northern storm track in the Pacific Ocean. Figure 16 shows the distribution of TC for the four different TC regions, including the total number fulfilling the $(6,6,4)$ criteria. As for the T213 there is a reduction of the number of TC in all regions except the Eastern Pacific. The North Indian Ocean has an even larger reduction, which could be a sampling error due to the small number of storms in the region, but an increase in a few very powerful storms. There is also a considerable increase in precipitation from 20C to 21C associated with the TC in T319. For a region of arc radius $2.5^{\circ}$ the area averaged precipitation increases by some $16 \%$. In summary, the T319 results support in all respects the results from T213 but having more intense storms than in T213.

For the overlapping years in the T213 and T319 experiments we compared the interannual variability of the number of TC between the two experiments ( $10 \mathrm{yr}$ for $20 \mathrm{C}$ and $20 \mathrm{yr}$ for $21 \mathrm{C}$ ). We found a close similarity in the annual variance but a rather poor correlation of the number of TC in specific regions between the two model experiments suggesting that the atmospheric circulation is only weakly constrained by the SST pattern.

Table 7. Summary of the number of TC per year whose maximum intensity in terms of vorticity at $850 \mathrm{hPa}$ exceed certain values, for T319

\begin{tabular}{lcccc}
\hline T319 & All $(6,6,4)$ & $>2 \times 10^{-4} \mathrm{~s}^{-1}$ & $>5 \times 10^{-4} \mathrm{~s}^{-1}$ & $>1 \times 10^{-3} \mathrm{~s}^{-1}$ \\
\hline 20C (1980-2000) & 101 & 100 & 71 & 30 \\
$21 \mathrm{C}(2080-2100)$ & 89 & 89 & 76 & 43 \\
\hline
\end{tabular}



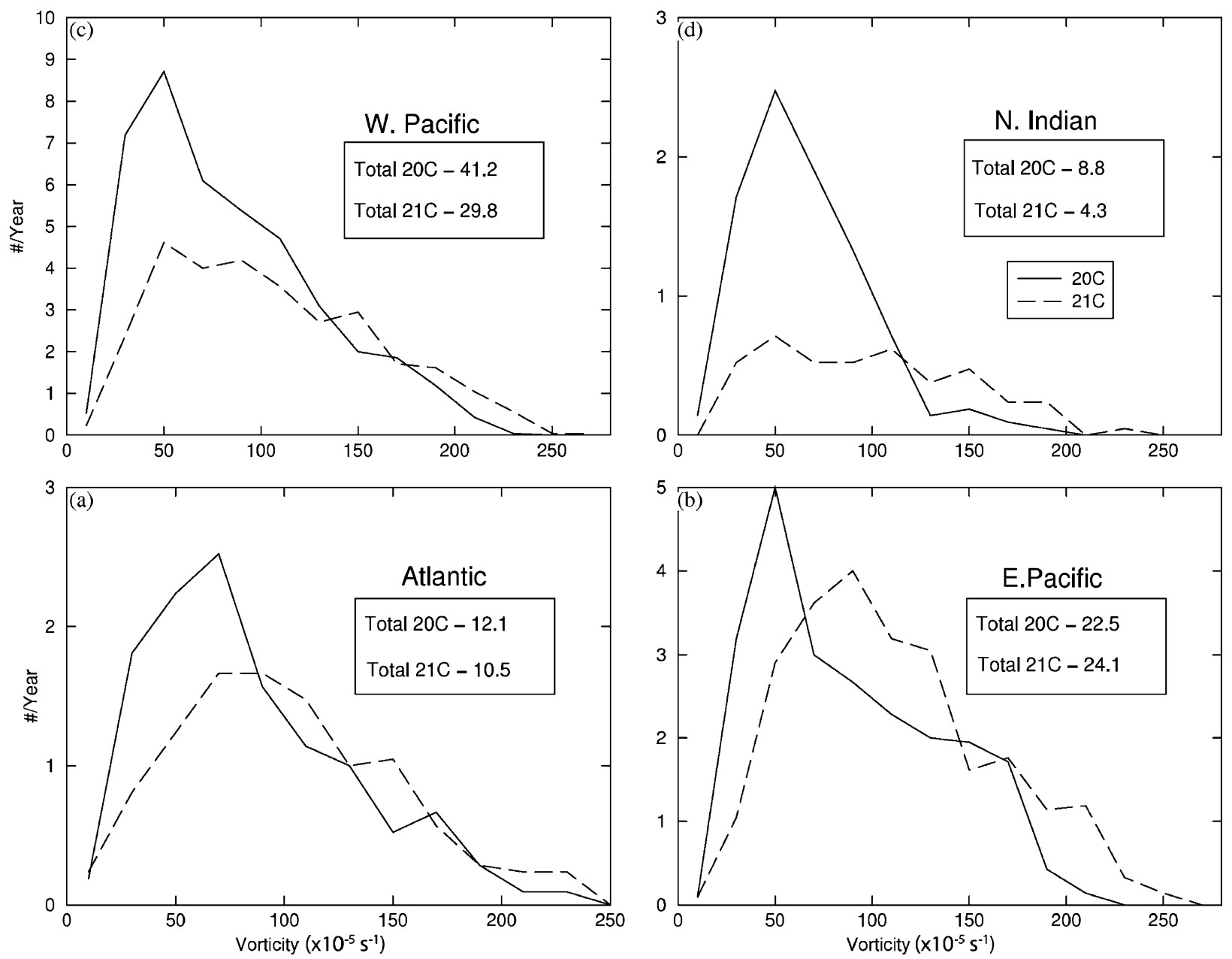

Fig. 16. T319 regional distributions of maximum attained intensity based on $850 \mathrm{hPa}$ relative vorticity for 20C and 21C for (a) Atlantic, (b) eastern Pacific, (c) western Pacific and (d) north Indian ocean. Bin widths are $2 \times 10^{-4} \mathrm{~s}^{-1}$. Inset boxes show the total number per year for each region and for $20 \mathrm{C}$ and $21 \mathrm{C}$, respectively.

\section{Discussion}

\subsection{How do the TC respond to an increase in resolution?}

The number of identified storms depends on resolution. Using the $(6,6,4)$ criteria (see Section 2$)$ the number of identified $\mathrm{TC}$ in T213 is almost three times as many as in T63 (Table 1), but the ratio diminishes when we reduce the vertical vorticity gradient. However, we have compared the results for T213 with the results from a T159 AMIP experiment using observed SST for the period 1979-1999 and notice an overall agreement in the number of TC ( $5 \%$ less compared to this study), their distribution and intensity (Bengtsson et al., 2007). The small increase in number compared to T159 could be due to the somewhat higher resolution used here, or the different SST used. We also note that the T319 experiment has a similar number of TC as in T213.

There is a marked increase in intensity as resolution increases. As can be seen from the Tables 1-5 and 7-8 the increase in intensity can be seen both in vorticity and maximum wind speed as well as a decrease in surface pressure (not shown). For T213 the maximum wind speed increases to $65 \mathrm{~m} \mathrm{~s}^{-1}$ in 20C and for T319 to $81 \mathrm{~m} \mathrm{~s}^{-1}$ although the T319 value is for $850 \mathrm{hPa}$ instead of $925 \mathrm{hPa}$. Whilst, T213 shows a large relative change in the number of the most intense storms $\left(\xi_{\max }>1.0 \times\right.$ $10^{-3} \mathrm{~s}^{-1}$, Table 4$), \sim 60 \%$ from $20 \mathrm{C}$ to $21 \mathrm{C}$, this is actually due to the small numbers involved. There is actually a larger increase in the number of the most intense storms in T319 from 20C to 21C (Table 7). This is also the case for wind speeds $>50 \mathrm{~m} \mathrm{~s}^{-1}$ (Tables 5 and 8 ).

Another noticeable effect is the reduction in size of the TC as resolution increases. Using the distance between the centre of the storm and the position of the maximum wind speed this is reduced from $340 \mathrm{~km}$ at T63 to $130 \mathrm{~km}$ at T319 as an average for the 100 most intense storms. The asymmetry of the radial and tangential wind agree generally well with typical observed TC with the maximum wind speed to the 
east of the centre and inflow to the south and outflow to the north.

\subsection{What changes occur in intensity, lifetime and power dissipation index in a warmer climate?}

This study shows that the number of TC will diminish in a warmer climate. This occurs independent of resolution, although the signal is more pronounced at the T63 resolution (though this could be associated with the identification criteria, since the identification criteria have been calibrated against operational analyses integrated at much higher resolution). This is in agreement with most previous studies (Bengtsson et al., 1996; Sugi et al., 2002; Yoshimura et al., 2006) but is also supported by recent experiments at very high resolution (Oouchi et al., 2006). As will be outlined below, this is likely to be due to the reduced tropical circulation, ultimately caused by the large increase in atmospheric water vapour.

The calculations show that there is no significant change in intensity at the T63 resolution, which is broadly in agreement with several other studies at low and medium resolution (Bengtsson et al., 1996; Sugi et al., 2002). However, this is not the case when resolution is further increased. The T213 experiment show a $60 \%$ increase in the most intense storms (based on $850 \mathrm{hPa}$ vorticity $>1 \times 10^{-3} \mathrm{~s}^{-1}$ ) and have $30 \%$ more TC with maximum wind speeds above $50 \mathrm{~ms}^{-1}$, storms in the category 3-5 of the Saffir/Simpson scale (according to winds at $925 \mathrm{hPa}$ ). The highest wind speed in $21 \mathrm{C}$ for $\mathrm{T} 213$ is $69 \mathrm{~m} \mathrm{~s}^{-1}$ compared to $65 \mathrm{~m} \mathrm{~s}^{-1}$ in $20 \mathrm{C}$ with the lowest central surface pressure in $21 \mathrm{C}$ being $921 \mathrm{hPa}$ compared to $925 \mathrm{hPa}$ in 20C. There is only a minor increase in the lifetime of TC between $20 \mathrm{C}$ and 21C. A similar proportional increase occurs in the T319 experiment having more intense storms in $21 \mathrm{C}$. The maximum wind speed at $850 \mathrm{hPa}$ increases from $81 \mathrm{~m} \mathrm{~s}^{-1}$ in $20 \mathrm{C}$ to $87 \mathrm{~m} \mathrm{~s}^{-1}$ in $21 \mathrm{C}$.

The interesting result obtained here is the change in the behaviour of the intense storms which clearly increase in intensity in a warmer climate by as much as $20-30 \%$ in the high resolution studies, indicated by the change in the numbers of storms with $\xi_{\max }>5.0 \times 10^{-4} \mathrm{~s}^{-1}$ or wind speeds $>33 \mathrm{~m} \mathrm{~s}^{-1}$ (Tables 4 , 5 and Tables 7, 8), but show no noticeable increase at lower resolution (Tables 2 and 3). The high-resolution result is in this respect in overall agreement with the results obtained by Oouchi et al., 2006. A possible explanation will be discussed below.

The effect of changed resolution cannot be determined unequivocally, as there are qualitative differences in the two experiments. This could be an effect of the lack of atmosphere-ocean interactions in the T213 runs as the lack of air-sea interaction may contribute to more intense cyclones (Emanuel et al., 2004). However, this is not expected to influence the change in TC, as the same limitation is valid for both the present and the future climate. As was found by Knutson et al., (2001) the change in intensification due to climate change between a coupled and uncoupled model is insignificant.
The PDI undergoes a minor increase by some $6 \%$ from $20 \mathrm{C}$ to $21 \mathrm{C}$, at $\mathrm{T} 213$, when calculated for all TC but increases by $16 \%$ if we restrict the calculation to vortices that reach the intensity of $33 \mathrm{~m} \mathrm{~s}^{-1}$ or higher during their lifetime. This is not a very robust measure since there are large variations from year-to-year. The increase in PDI is due to higher maximum wind speeds and to slightly longer lifetimes of the TC in $21 \mathrm{C}$ slightly offset by the smaller number of TC in $21 \mathrm{C}$.

\subsection{Why do we have less TC in a warmer climate?}

Empirical studies (Palmen, 1948) and long records of observations since then support the perception that SST at around $26^{\circ} \mathrm{C}$ or higher are required for the development of TC. At first approximation it therefore seems reasonable to assume that higher SST would be favourable for the development of more TC as ocean areas with SST above $26^{\circ} \mathrm{C}$ will extend. While tropical SST has increased by about $0.5^{\circ} \mathrm{C}$ during the last $50 \mathrm{yr}$ there are no reliable indications of an increase in the number of tropical storms, but instead non-periodic variations with a standard deviation of around $10 \%$ of the average annual number of 85 (Northern Hemisphere some 60). The number of TC in this study are somewhat higher due to the definition of a TC used here. However, there are indications from observations from recent years that the number may be higher and closer to the numbers obtained in the model experiment as observational systems are now more comprehensive and reporting procedures are more systematic.

The experiment reported here, as well as recent climate change studies (Sugi et al., 2002; Oouchi et al., 2006), indicate that the number of simulated tropical storms do not increase with higher SST but rather diminish in number. This appears to be valid for a range of different parametrization schemes (Yoshimura et al., 2006). Neither is it a question of insufficient model resolution as we see the same at a resolution as high as $20 \mathrm{~km}$ (Oouchi et al., 2006). Several studies also claim that the distribution of tropical storms is rather related to the distribution of SST anomalies and not directly to their amplitudes (e.g. Yoshimura et al., 2006, their fig. 10). The reason is that the tropical circulation is strongly influenced by SST anomalies and the tropical circulation is crucial for the development of TC.

The increase in the static stability, shown in, Fig. 17, is because convection follows a less steep lapse rate in the warmer and moister climate and the increase is to first approximation proportional to the increase in specific humidity. Following the presentation by Sugi et al. (2002) the approximate energy equation in the tropics can be formulated as:

$w \frac{\partial \theta}{\partial p} \approx \frac{\theta}{T} \frac{Q}{c_{\mathrm{p}}}$

(Holton 1992; Knutson and Manabe, 1995). The energy balance for upward and downward motion, respectively at $500 \mathrm{hPa}$ can 


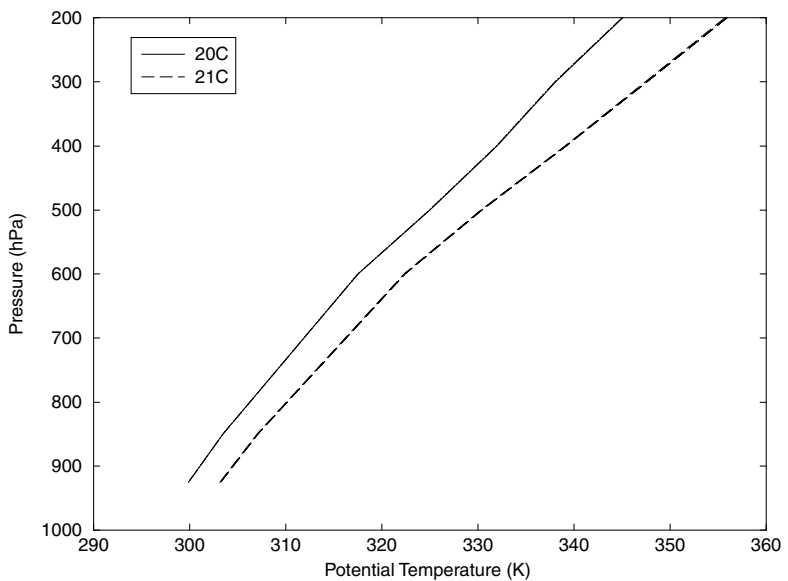

Fig. 17. Static stability for $20 \mathrm{C}$ and $21 \mathrm{C}$ computed from the T63 monthly data, averaged over July-October and between latitudes $(-30$, $30)$.

be written as:

$M_{\mathrm{u}}\left|\frac{\partial \theta}{\partial p}\right| \approx \frac{\theta}{T} \frac{1}{c_{\mathrm{p}}}\left(Q_{\mathrm{C}}-Q_{\mathrm{R}}\right) A_{\mathrm{u}}$,

$M_{\mathrm{d}}\left|\frac{\partial \theta}{\partial p}\right| \approx \frac{\theta}{T} \frac{1}{c_{\mathrm{p}}} Q_{\mathrm{R}} A_{\mathrm{d}}$,

where $M_{\mathrm{u}}$ and $M_{\mathrm{d}}$ are the mass fluxes and $A_{\mathrm{u}}$ and $A_{\mathrm{d}}$ are the corresponding fractional areas. $Q_{\mathrm{C}}$ and $Q_{\mathrm{R}}$ are the condensation heating and radiative cooling rates, respectively. In Table 9 we summarize the results from the T63 experiments. As can be seen there is a reduction in the tropical mass flux in $21 \mathrm{C}$. We represent here the mass flux by the vertical velocity in $\mathrm{m} \mathrm{Pa} \mathrm{s}^{-1}$ as an average for the months July-October. As can be seen from the table there is a general reduction in the tropical mass flux as the change in the heating rates are proportional to the precipitation rates (increasing by some $6 \%$ ) while the change in static stability is related to the increase in specific humidity (increasing by some $26 \%$ ). We have not been able to calculate the instantaneous fluxes which we expect to show larger differences (see Sugi et al., 2002, their table 3).

Table 9. Mean tropical mass fluxes for the three 30-yr experiments at T63 (Unit, $\mathrm{mPa} \mathrm{s}^{-1}$ ) for the July-October period

\begin{tabular}{|c|c|c|c|c|c|c|}
\hline & \multicolumn{2}{|c|}{$20 \mathrm{C}$} & \multicolumn{2}{|c|}{$21 \mathrm{C}$} & \multicolumn{2}{|c|}{$\%$ difference } \\
\hline & Mass flux & Area & Mass flux & Area & Mass flux & Area \\
\hline \multirow[t]{3}{*}{ Upward } & 31.8 & 0.409 & 30.7 & 0.409 & -3.5 & 0.0 \\
\hline & 31.6 & 0.413 & 31.2 & 0.403 & -1.3 & -2.4 \\
\hline & 31.9 & 0.410 & 31.1 & 0.409 & -2.5 & 0.0 \\
\hline \multirow[t]{3}{*}{ Downward } & 24.7 & 0.591 & 22.9 & 0.591 & -7.3 & 0.0 \\
\hline & 25.1 & 0.587 & 22.5 & 0.597 & -10.4 & +1.7 \\
\hline & 25.2 & 0.590 & 23.1 & 0.591 & -8.3 & 0.0 \\
\hline
\end{tabular}

Another indication of a weakening of the tropical circulation is the increased residence time of atmospheric water vapour. General circulation models, without exception, show a larger increase in atmospheric water vapour than in precipitation (Held and Soden, 2006). ECHAM5 at both T63 and T213 resolutions shows an increase in the average residence time, from $20 \mathrm{C}$ to $21 \mathrm{C}$, of water in the atmosphere from 8.7 to $10.3 \mathrm{~d}$, or by $19 \%$. A similar percentage increase is seen in the tropics (30S-30N).

Whether this would imply a reduced frequency of tropical storms is not obvious from these general considerations. However, we have examined changes in the fields of velocity potential between 20C and 21C (not shown) for the main activity period (July-October), which controls the large-scale convergence pattern in the tropics. This shows a minor weakening and so does the associated large-scale Walker circulation in the equatorial plane. We have also considered the differences in the vertical shear for this period (not shown) which indicates an increase in shear in the western Pacific and the Bay of Bengal and a reduction in the eastern Pacific and northern Caribbean. This will modulate the favourable conditions required for the generation and growth of onset vortices in a warmer and moister atmosphere.

\subsection{Why do we have more intense TC in a warmer climate?}

During the period of a long integration favourable conditions for cyclone development are likely to occur by chance. Under such situations the optimum conditions as estimated by Emanuel (1988) and Holland (1997) could be considered as an upper limit in calculating the maximum condition in wind speed and vorticity and minimum condition in surface pressure. The result here is highly dependent on horizontal resolution with a gradual intensification as the grid distance is reduced. Using the condition $(6,6,4)$ for a typical warm core TC the number of cyclones for resolutions in the range T159-T319 is around 100 per year with a standard deviation of 10-12. However, the number of weaker TC decrease and the intense TC increase as we successively increase resolution (Fig. 15a). But even at the highest resolution tested here the detailed structure of the core of the cyclone cannot be correctly simulated. Experiments with limited area models (Shen et al., 2006) suggest that a resolution of a few kilometres is probably required to model and predict the dynamics of the core and consequently the extreme wind structure of the centre of the storm.

\section{Concluding remarks}

The results from this study support recent results by highresolution global models (Oouchi et al., 2006) as well as experiments with limited area models (Knutson and Tuleya, 2004). It highlights the need to increase the resolution in climate 
modelling studies to capture the correct structure of TC and to negate incorrect conclusions being made from model experiments having insufficient resolution. We are not able here to advice on any preferred resolution but indications are that a horizontal grid mesh of some $50 \mathrm{~km}$ or equivalent should rather be seen as an upper limit and all effort should be made to undertake experiments with resolution sufficient to resolve the key aspects of TC dynamics and thermodynamics. Lacking sufficient computer resources an alternative experimental approach could be considered. As has been demonstrated here and in other studies reported in this paper present general circulation models are generally able to simulate the generation, evolution and movements of TC but underestimate their intensity and detailed structure. For this reason we must conclude that the coarse resolution models have deficiencies in properly responding to higher SST. This could be overcome by running selected events in situations when modelled storms occur for short periods, but using much higher resolution, so that it is possible to better describe the dynamics and thermodynamics of intense TC. We intend to explore such integrations in a future study. Another approach would be to use adaptive grid techniques, for example Jablonowski et al. (2004) but require a model configured in this way.

We have for practical reasons restricted the study to the ECHAM5/MPI-OM model. Recent assessments indicate that this model is one of the most accurate in reproducing the present climate. However, the model has some systematic errors including a too high SST along the west coast of central and southern Africa and on the west coast of northern Chile and Peru. This affects the position and intensity of the ITCZ in these regions and also the position of easterly waves. This tendency is further enhanced in $21 \mathrm{C}$ giving rise to very high temperatures in these regions due to reduced cloudiness and enhanced solar absorption in upper ocean layers. In the Atlantic area this may contribute to the intensification of easterly waves over western Africa. In the Pacific the SST warming pattern may contribute to the activation of the TC in the eastern Pacific reminiscent of situations typical for ENSO events. The model has rather realistic ENSO events (Oldenbourgh et al., 2005) but also has a superimposed warming in the ENSO region as seen in Fig. 1.

For this reason we believe it would be highly interesting to undertake similar experiments, as we have done here, with other models including those which may not have the same systematic errors. It is imperative for this, that sufficient fields and levels be archived at higher temporal frequency (6 hourly) than is typically the case for climate model integrations.

Another important aspect is to better understand the sensitivity to the parametrization of processes such as convection, cloud precipitation mechanisms and turbulence typical of intense tropical vortices. We therefore believe that it is required to explore this along the lines as has been done by Yoshimura et al. (2006). This should include if possible limited studies of explicit treatment of the physical processes in TC. Needless to say, this will not exclude alternative approaches to estimate changes of TC in a warmer climate. An interesting approach to estimate the change in TC has been suggested by Emanuel (2006). He used a combination of statistically generated storm tracks combined with an idealized axisymmetric model of a tropical cyclone. The dynamical model considers interactions with the ocean but some atmospheric aspects important for the intensity estimates such as changes in wind shear are parametrized. A possible approach to consider in future studies would be to combine storm tracks calculated by a large-scale model and then use such model generated storm tracks to drive an idealized model of the kind used by Emanuel (ibid), which could then be used for an independent estimate of intensity.

We finally note that the maximum wind speed in $21 \mathrm{C}$ increases by $6 \%$ for $\mathrm{T} 213$ and $8 \%$ for $\mathrm{T} 319$, which is about the same, $6 \%$, as was obtained in the study by Knutson and Tuleya (2004) using a limited area model but with the large-scale conditions from the coupled model experiment project, CMIP2+. The CMIP2+ experiment uses an assumed increase of greenhouse gases equivalent to $1 \%$ annually over $80 \mathrm{yr}$. The SST at that time for most of the models were around $2^{\circ} \mathrm{C}$ higher or slightly less than in this study. We may thus agree with the conclusions from Knutson and Tuleya (ibid) that a period of at least some $20 \mathrm{yr}$ may be required for the possible detection of a genuine intensification of TC under the A1B scenario. Consequently, under these general assumptions, and that we may consider the model results as credible, the claim that present trends in TC intensification are caused by climate change are presumably not robust but more likely due to natural variability.

\section{Acknowledgments}

The coupled model integrations were performed at the German Climate Computing Centre (DKRZ) in Hamburg. The T213 time-slice integrations where performed at ECMWF in Reading, UK and Norddeutscher Verbund für Hoch-und Höchstleistungsrechnen (HLRN), Germany and the T319 time-slice integrations at the Earth Simulator in Yokohama, Japan. The research was financed in part by the German Ministry for Education and Research (BMBF) under the DEKLIM project and the EU project ENSEMBLES (GOCE-CT-2003-505539).

\section{Appendix A}

Storm composites have occasionally been used in the past to illustrate the typical structure of particular types of storms. This approach is perhaps most easily applied to TC, for example, see Chauvin et al. (2006, their fig. 11) and Frank (1977), since they are predominately only found in the tropics and subtropics. The compositing can then be performed on the latitude-longitude data grid without too much bias associated with using a cylindrical projection for what are in reality spherical data. Bias is introduced when using any kind of projection for 
global spherical data since the shape and area of a chosen region on the projection are not both conserved on the sphere. However, some storms can still be considered TC as they progress into the mid-latitudes and it is important to remove bias where ever possible from the analysis. Rather surprisingly, compositing on latitude-longitude regions has also been applied to extratropical storms where it is even more unsuitable unless performed on a small latitudinal band where the grid distortion may be less important.

To get around these problems we introduce a method, similar to that originally used by Frank (1977), for obtaining composites which works directly on the sphere and so can be applied anywhere on the sphere without the introduction of bias. This entails defining a radial grid with respect to a spherical cap region centred on the pole and then rotating this grid to be centred on the storm centre and sampling the chosen field at the new gridpoints. Working in spherical polar coordinates $(\theta, \varphi)$ we specify a spherical cap by choosing a value for the arc radius $\theta_{\mathrm{a}}$, then distributing points evenly in $\left(0, \theta_{\mathrm{a}}\right)$ for $\theta$ and $(0,360)$ for $\varphi$. These are then converted to 3 -D Cartesian vectors $(x, y, z)$ representing points on the unit sphere. To rotate this grid in a consistent way to be centred on the storm centres we use the rotation matrix A.

$A=\left[\begin{array}{ccc}\cos \phi \cos \theta & -\sin \phi & \cos \phi \sin \theta \\ \sin \phi \cos \theta & \cos \phi & \sin \phi \sin \theta \\ -\sin \theta & 0 & \cos \theta\end{array}\right]$,

where $(\theta, \varphi)$ here are the co-latitude and longitude of the storm centre. This is equivalent to a rotation in $\theta$ followed by a rotation in $\varphi$. So the new grid is centred on a storm centre by applying $\hat{\mathbf{x}}^{\prime}=\mathrm{A} \hat{\mathbf{x}}$ to each of the radial grid unit vectors. Once the grid has been centred on a storm centre the unit vectors are converted back to latitudes and longitudes for sampling the required field.
The required field is sampled at these new points by interpolating the field with B-splines on the original data latitudelongitude grid and the field values determined on the new storm centred grid. This is done for all 6 hourly positions along the track and the fields stored for the compositing. This allows any choice of composites to be produced without having to re-read the full data set. Since following the rotation the grid is always orientated in a consistent way the new values can simply be accumulated on the new grid to produce the composites. However, for vector data, such as winds, we want to determine the vector components relative to the new grid and not the latitude-longitude grid (or spherical polar coordinates). Hence, for winds this entails determining the tangential and radial wind components of the wind vectors relative to the new grid. A schematic of how this is done is shown in Fig. A1. This shows how the new local coordinate system consisting of the tangential and radial unit vectors, $\hat{\mathbf{e}}_{t}$ and $\hat{\mathbf{e}}_{r}$, are derived from the polar coordinate system of $\hat{\mathbf{e}}_{\theta}$ and $\hat{\mathbf{e}}_{\phi}$ for a new gridpoint, represented by the unit vector $\hat{\boldsymbol{P}}_{\boldsymbol{G}}$, for the new grid centred on a TC point, represented by the unit vector $\hat{\boldsymbol{P}}_{\boldsymbol{T C}}$. The new vector wind components are then obtained from the dot product of $\hat{\mathbf{e}}_{t}$ and $\hat{\mathbf{e}}_{r}$ with the original wind vector $\boldsymbol{V}$. Note, the negative sign for the $\mathrm{V}$ component of $\boldsymbol{V}$ is due to $\mathrm{V}$ usually being taken as positive in the northerly direction whereas $\hat{\mathbf{e}}_{\theta}$ points in a southerly direction.

This methodology will produce composites that are based on a consistent orientation of the new grid. However, it is also of interest to re-orientate the grid with the direction of motion of the storm to determine the motion dependence of any asymmetries in the storm structure. This can be done with the application of Rodrigues' formula (Goldstein, 1980), for the rotation by the angle $\psi$ about a general axis $\hat{\boldsymbol{n}}$ :-

$\hat{\mathbf{x}}^{\prime}=\cos \psi \hat{\mathbf{x}}+(1-\cos \psi)(\hat{\mathbf{x}} \cdot \hat{\boldsymbol{n}}) \hat{\boldsymbol{n}}+\sin \psi \hat{\mathbf{x}} \times \hat{\boldsymbol{n}}$

\footnotetext{
Fig. A1. Schematic for determining the radial and tangential winds for a point on the spherical cap grid.
}

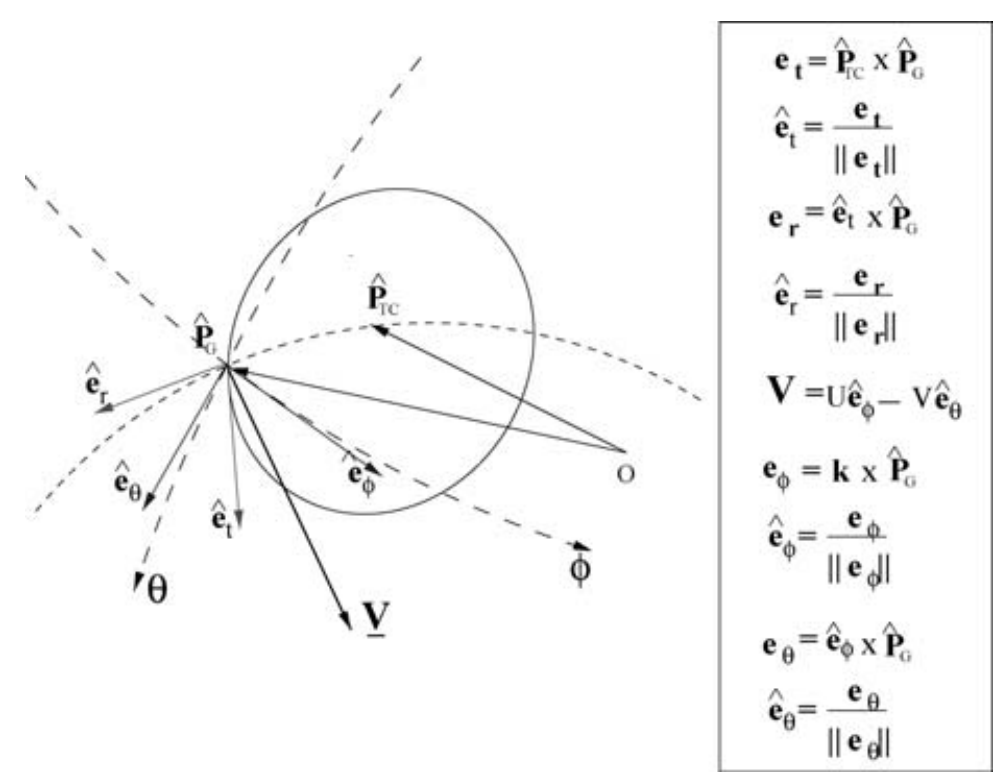


this can also be written in vector-matrix form but is perhaps most easily evaluated in this form. Hence, for $\hat{\boldsymbol{n}}=\hat{\boldsymbol{P}}_{T C}$ this will rotate our radial grid by the angle $\psi$. This angle is determined as the angle between the two unit tangent vectors for the direction of the storm and the initial orientation of the grid.

\section{References}

Bengtsson, L., Botzet, M. and Esch, M., 1995. Hurricane-type vortices in a general circulation model. Tellus 47A, 175-196.

Bengtsson, L., Botzet, M. and Esch, M. 1996. Will greenhouse gasinduced warming over the next 50 years lead to higher frequency and greater intensity of hurricanes? Tellus 48A, 57-73.

Bengtsson, L., Hodges, K. I. and Roeckner, E. 2006. Storm tracks and climate change. J. Clim. 19, 3518-3543.

Bengtsson, L., Hodges, K. I. and Esch, M. 2007. Hurricane type vortices in a high-resolution global model: comparison with observations and Re-Analyses. Tellus 59A, in press.

Bister, M. and Emanuel, K. A. 1998. Dissipative heating and hurricane intensity. Meteor. Atm. Phys. 52, 233-240.

Broccoli, A. J. and Manabe, S. 1990. Can existing climate models be used to study anthropogenic changes in tropical cyclone climate? Geophys. Res. Lett. 17, 1917-1920.

Chan J. C. L. 2006. Comments on "Changes in tropical cyclone number, duration, and intensity in a warming environment". Science 311, $1713 b$.

Chauvin, F., Royer, J.-F. and Déque, M. 2006. Response of hurricanetype vortices to global warming as simulated by ARPEGE-Climat at high resolution. Clim. Dyn. 27, 377-399.

DeMaria, M., Mainelli, M., Shay, L. K., Knaff, J. A. and Kaplan, J. 2005. Further improvements to the statistical hurricane intensity prediction scheme (SHIPS). Wea. Forecast. 20, 531-543.

Emanuel, K. A. 1987. The dependence of hurricane intensity on climate. Nature 326, 483-485.

Emanuel, K. A. 1988. The maximum intensity of hurricanes. J. Atmos. Sci. 45, 1143-1155.

Emanuel, K. A. 2005. Increasing destructiveness of tropical cyclones over the past 30 years. Nature 436, 686-688.

Emanuel, K., DesAutels, C., Holloway, C. and Korty, R. 2004. Environmental control of tropical intensity. J. Atmos. Sci. 61, 843-858.

Franks, W. M. 1977. The structure and energetics of the tropical cyclone I. Storm structure. Mon. Wea. Rev. 105, 1119-1135.

Goldstein, H. 1980. Finite rotations. In: Classical Mechanics, 2nd edn., Addison-Wesley, Reading, MA, pp. 164-166.

Gray, W. M. 1979. Hurricanes: their formation, structure and likely role in the tropical circulation. In: Meteorology Over Tropical Oceans (ed.D. B. Shaw), Roy. Meteor. Soc., James Glaisher House, Grenville Place, Bracknell, Berkshire, RG12 1BX, pp.155-218.

Held, I. M. and Soden, B. J. 2006. Robust responses of the hydrological cycle to global warming. J. Clim. 19, 5686-5699.

Holland G. J. 1997. The maximum potential intensity of tropical cyclones. J. Atmos. Sci. 54, 2519-2541.

Holton, J. R. 1992. An Introduction to Dynamical Meteorology. Academic Press, San Diego, 511 pp.

IPCC 2001. Climate Change 2001. The scientific basis. In: Contribution of Working Group I to the Third Assessment Report of the Intergov- ernmental Panel of Climate Change (eds J. T. Houghton, Y. Ding, D. J. Griggs, M. Noguer, P. J. vander Linden, X. Dai, K. Maskell and C. A. Johnson), Cambridge University Press, pp. 881.

Jablonowski, C., Herzog, M., Penner, J. E., Oehmke, R. C., Stout, Q. F. and co-authors. 2004. Adaptive grids for weather and climate models, ECMWF Seminar Proceedings on Recent Developments in Numerical Methods for Atmosphere and Ocean Modeling, pp. 233-250, Reading, UK.

Jungclaus, H., Keenlyside, N., Botzet, M., Haak, H., Luo, J.-J. and coauthors. 2006. Ocean circulation and tropical variability in the coupled model ECHAM5/MPI-OM. J. Clim. 19, 3952-3972.

Kepert, J. D. 2006a. Observed boundary layer wind structure and balance in the hurricane core. Part I: Hurricane Georges. J. Atmos. Sci. 63, 2169-2193.

Kepert, J. D. 2006b. Observed boundary layer wind structure and balance in the hurricane core. Part II: Hurricane Mitch. J. Atmos. Sci. 63, 21692193.

Knutson, T. R. and Manabe, S. 1995. Time-mean response over the tropical Pacific to increased $\mathrm{CO}_{2}$ in a coupled ocean-atmosphere model. J. Clim. 8, 2181-2199.

Knutson, T. R., Tuleya, R. E., and Kurihara, Y. 1998. Simulated increase of hurricane intensities in a $\mathrm{CO}_{2}$-warmed climate. Science 279, 1018 1020.

Knutson, T. R. and Tuleya, R. E. 1999. Increased hurricane intensities with $\mathrm{CO}_{2}$-induced global warming as simulated using the GFDL hurricane prediction system. Clim. Dyn. 15, 503-519.

Knutson, T. K., Tuleya, R. E., Shen, W. and Ginnis, I. 2001. Impact of $\mathrm{CO}_{2}$-induced warming on hurricane intensities as simulated in a hurricane model with ocean coupling. J. Clim. 14, 2458-2468.

Knutson, T. K. and Tuleya, R. E. 2004. Impact of CO2-induced warming on simulated hurricane intensity and precipitation: sensitivity to the choice of climate model and convective parameterization. J. Clim. 17, 3477-3495.

Klotzbach, P. J. 2006. Trends in global tropical cyclone activity over the past twenty years (1986-2005). Geophys. Res. Lett. 33, L10805, doi:10.1029/2006GL025881.

Krishnamurti, T. N., Pattnaik, S., Stefanova, L., Vijaya Kumar, T. S. V. and co-authors. 2005. The hurricane intensity issue. Mon. Weather Rev. 133, 1886-1912.

Landsea, C. W., Harper, B. A., Hoarau, K. and Knaff, J. A. 2006. Can we detect trends in extreme tropical cyclones? Science 313, 452454.

Lin, J.-L., Kiladis, G. N., Mapes, B. E., Weickmann, K. M., Sperber, K. R. and co-authors. 2006. Tropical intraseasonal variability in 14 IPCC AR4 climate models. Part I: Convective signals. J. Clim. 19, 2665-2690.

Nakicenovic, N., Alcamo, J., Davis, G., de Vries, B., Fenhann, J. and co-authors. 2000. IPCC Special Report on Emissions Scenarios. Cambridge University Press, Cambridge, United Kingdom and New York, NY, USA. 599 pp.

Oldenborgh, G. J. van Philip, S. Y. and Collins, M. 2005. El Niño in a changing climate: a multi-model study. Ocean Sci. 1, 81-95.

Oouchi, K., Yoshimura, J., Yoshimura, H., Mizuta, R., Kusunoki, S. and co-authors. 2006. Tropical cyclone climatology in a global-warming climate as simulated in a $20 \mathrm{~km}$-mesh global atmospheric model: frequency and wind intensity analysis. J. Meteorol. Soc. Jpn. 84, 259276. 
Palmen, E. H. 1948. On the formation and structure of tropical cyclones. Geophysica 3, 26-38.

Pham, M., Boucher, O. and Hauglustaine, D. 2005. Changes in atmospheric sulfur burdens and concentrations and resulting radiative forcings under IPCC SRES emission scenarios for 1990-2100. J. Geophys. Res. 110, D06112, doi:10.1029/2004JD005125.

Rayner, N. A., Brohan, P., Parker, D. E., Folland, C. K., Kennedy, J. J. and co-authors. 2006. Improved analyses of changes and uncertainties in sea surface temperature measured in situ since the mid-nineteenth century: the HadSST2 data set. J. Clim. 19, 446-469.

Roeckner, E., Brasseur, G. P., Giorgetta, M., Jacob, D., Jungclaus, J. and co-authors. 2006. Climate projections for the 21st century. Max Planck Institute for Meteorology, Internal Report, 28 pp. [available from Max Planck Institute for Meteorology, Bundesstr. 53, 20146, Hamburg, Germany].

Royer, J.-F., Chauvin, F., Timbal, B., Araspin, P. and Grimal, D. 1998. A GCM study of impact of greenhouse gas increase on the frequency of occurrence of tropical cyclones. Clim. Dyn. 38, 307343.

Ryan, B. F., Watterson, I. G. and Evans, J. L. 1992. Tropical cyclone frequencies inferred from Gray's yearly genesis parameter: Validation of GCM tropical climate. Geophys. Res. Lett. 19, 1831-1834.

Shen, B.-W., Atlas, R., Reale, O., Lin, S.-J., Chern, J.-D. and co-authors. 2006. Hurricane forecasts with a global mesoscale-resolving model: preliminary results with Hurricane Katrina (2005). Geophys. Res. Lett. 33, L13813, doi: 10.1029/2006GL026143.

Sriver, R. L. and Huber, M. 2006. Low frequency variability in globally integrated tropical cyclone power dissipation. Geophys. Res. Lett. 33, L11705 doi:10.1029/2006GL026167.
Sugi, M., Noda, A. and Sato, N. 2002. Influence of the global warming on tropical cyclone climatology: an experiment with the JMA global model. J. Meteorol. Soc. Jpn. 80, 249-272.

Tang, B. H. and Neelin, J. D. 2004. ENSO influence on Atlantic hurricanes via tropospheric warming. Geophys. Res. Lett. 31, L24204, doi:10.1029/2004GL021072.

Thorncroft, C. and Hodges, K. 2001. African easterly wave variability and its relationship to atlantic tropical cyclone activity. J. Clim. 14, 1166-1179.

Walsh, K., Fiorino, M., Landsea, C. and McInnes, K. 2007. Objectivelydetermined resolution-dependent threshold criteria for the detection of tropical cyclones in climate models and reanalyses. J. Clim., in press

Watterson, I. G., Evans, J. L. and Ryan, B. F. 1995. Seasonal and interannual variability of tropical cyclogenesis: diagnostics from large-scale fields. J. Clim. 8, 3042-3066.

Webster, P. J., Holland, G. J., Curry, J. A. and Chang, H. R. 2005. Changes in tropical cyclone number, duration, and intensity in a warming environment. Science 309, 1844-1846.

WGNE 1996. AMIP II guidelines. Atmospheric Model Intercomparison Project Newsletter, No. 8, AMIP Project Office, Livermore, CA, 24 pp. [Available from AMIP Project Office, PCMDI, L-264, LLNL, P.O. Box 808, Livermore, CA 94550.].

Wu, G. and Lau, N.-C. 1992. A GCM simulation of the relationship between tropical-storm formation and ENSO. Mon. Wea. Rev. 120, 958-977.

Yoshimura, J., Masato, S. and Noda, A. 2006. Influence of greenhouse warming on tropical cyclone frequency. J. Meteorol. Soc. Jpn. 84(2), $405-428$. 